\title{
Functional Materials Based on Cyclometalated Platinum(II) $\beta$-Diketonate Complexes: A Review of Structure-Property Relationships and Applications
}

\author{
Ashanul Haque ${ }^{1, *(\mathbb{D}, \text { Hani El Moll }}{ }^{1}$ (D), Khalaf M. Alenezi ${ }^{1}$, Muhammad S. Khan ${ }^{2, *(D)}$ and Wai-Yeung Wong ${ }^{3, *(D)}$ \\ 1 Department of Chemistry, College of Science, University of Hail, Ha'il 81451, Saudi Arabia; \\ h.elmoll@uoh.edu.sa (H.E.M.); k.alenezi@uoh.edu.sa (K.M.A.) \\ 2 Department of Chemistry, Sultan Qaboos University, P.O. Box 36, Al-Khod 123, Oman \\ 3 Department of Applied Biology and Chemical Technology, The Hong Kong Polytechnic University, \\ Hung Hom, Kowloon, Hong Kong, China \\ * Correspondence: a.haque@uoh.edu.sa (A.H.); msk@squ.edu.om (M.S.K.); \\ wai-yeung.wong@polyu.edu.hk (W.-Y.W.)
}

check for updates

Citation: Haque, A.; El Moll, H.; Alenezi, K.M.; Khan, M.S.; Wong, W.-Y. Functional Materials Based on Cyclometalated Platinum(II) $\beta$-Diketonate Complexes: A Review of Structure-Property Relationships and Applications. Materials 2021, 14 , 4236. https://doi.org/10.3390/ ma14154236

Academic Editor: Juan F. Van der Maelen

Received: 3 June 2021

Accepted: 26 July 2021

Published: 29 July 2021

Publisher's Note: MDPI stays neutra with regard to jurisdictional claims in published maps and institutional affiliations.

Copyright: (c) 2021 by the authors. Licensee MDPI, Basel, Switzerland. This article is an open access article distributed under the terms and conditions of the Creative Commons Attribution (CC BY) license (https:// creativecommons.org/licenses/by/ $4.0 /)$.

\begin{abstract}
Square planar organoplatinum(II) complexes have garnered immense interest in the area of materials research. The combination of the $\mathrm{Pt}(\mathrm{II})$ fragment with mono-, bi- tri- and tetradentate organic ligands gives rise to a large variety of complexes with intriguing properties, especially cyclometalated $\mathrm{Pt}(\mathrm{II})$ complexes in which ligands are connected through covalent bonds demonstrate higher stability, excellent photoluminescence properties, and diverse applications. The properties and applications of the Pt(II)-based materials can be smartly fine-tuned via a judicious selection of the cyclometalating as well as ancillary ligands. In this review, attempts have been made to provide a brief review of the recent developments of neutral $\mathrm{Pt}(\mathrm{II})$ organometallic complexes bearing bidentate cyclometalating ligands and $\beta$-diketonate ancillary ligands, i.e., $\left(\mathrm{C}^{\wedge} \mathrm{N}\right) \mathrm{Pt}\left(\mathrm{O}^{\wedge} \mathrm{O}\right)$ and $\left(\mathrm{C}^{\wedge} \mathrm{C}\right) \mathrm{Pt}\left(\mathrm{O}^{\wedge} \mathrm{O}\right)$ derivatives. Both small (monomeric, dimeric) and large (polymeric) materials have been considered. We critically assessed the role of functionalities (ligands) on photophysical properties and their impact on applications.
\end{abstract}

Keywords: cyclometalated; platinum(II); $\beta$-diketonate; opto-electronics; square planar

\section{Introduction}

The last few decades have witnessed a great upsurge in the design and development of organometallic materials owing to their fascinating structures, intriguing properties and diverse applications [1,2]. Among a large number of organometallic materials, phosphorescent square planar $\mathrm{Pt}(\mathrm{II})$ complexes have gained particular interest [3-5]. This is indeed due to the inherent ability of heavy $\mathrm{Pt}$ (II) fragments to induce strong spin-orbit coupling (SOC), leading to intersystem crossing (ISC) as well as access to the spin-forbidden triplet radiative decay [6,7]. Consequently, $\mathrm{Pt}(\mathrm{II})$ complexes grafted in the main chains or side chains exhibit high triplet quantum yield $\left(\Phi_{\mathrm{T}}\right)$, long triplet excited state lifetime $\left(\tau_{\mathrm{T}}\right)$ and several other interesting photophysical properties [8]. In addition, due to the square planar coordination geometry around $\mathrm{Pt}(\mathrm{II})$ center, they often show molecular stacking supported by metallophilic and other noncovalent interactions (NCI) leading to altered emission features (such as excimeric emission).

In $\mathrm{Pt}(\mathrm{II})$ complexes, the photophysical and photochemical properties are highly sensitive to the type of the coordinating ligands. Through judicious selection of the ligands and their coordinating modes, the optical properties can be easily manipulated. Compared to the coordinate bonds, linkage of a metal to the organic core via one or more covalent bonds is highly beneficial as it imparts greater stability to the resulting complexes [9]. Studies suggest that the ligation of a strong electron-withdrawing cyclometalating ligand to a transition metal raises the energy of the metal-centered (MC) states to avoid nonradiative 
decay $[3,10,11]$. This leads to a significant impact on the emission parameters such as quantum yield $(\Phi)$ and lifetime $(\tau)$ values as well as color [12].

Cyclometalating ligands also offer an excellent platform for modulating NCI, which play a substantial role in determining the nature of photoluminescence (PL) [13]. Therefore, such ligands serve as excellent candidates for the design of new functional materials. Among different bi-, tri- and tetradentate ligands, the use of a bidentate ligand is particularly beneficial as it imparts high tunability of structural features and electronic properties to the Pt(II) complexes [14]. It has been demonstrated that the cyclometalated Pt(II) complexes induce greater SOC compared to other $\sigma$-bonded $\mathrm{Pt}(\mathrm{II})$ complexes such as platinaynes [15] and that the extent of SOC can be further enhanced by increasing the number of metal units [16].

In addition to the cyclometalating ligands and metallic core, the nature of ancillary ligand also plays a crucial role in the determination of physicochemical and photophysical properties [17]. Among the large variety of ancillary ligands, one very common and popular family is provided by $\beta$-diketonate derivatives [17-21]. The incorporation of structurally diverse $\beta$-diketonate ancillary ligands not only improves the physicochemical properties [18,19], but also alters molecular separation/stacking [17] induces liquid crystallinity [20] and governs the exciton generation and transport. It has been shown that the $\Phi$ and $\tau$ values can be readily improved simply by extending the ancillary ligand $\pi$-system [3,21].

Fascinated by the features of $\mathrm{Pt}(\mathrm{II})$ ion, bidentate cyclometalating organic core, and $\beta$-diketonate, a diverse range of small (monomeric, dimeric) and large (polymeric) complexes/materials have been developed in recent times [14]. These materials have been realized via smart selection of the $\mathrm{C}^{\wedge} \mathrm{N}$ - or $\mathrm{C}^{\wedge} \mathrm{C}^{*}$-cyclometalating ligands and $\beta$-diketonate ancillary ligands. $\mathrm{Pt}(\mathrm{II})$ complexes with $\beta$-diketonate ligands have been studied intensively, but they are not reviewed very often [14,22]. This motivated us to provide a brief and up-to-date review on neutral $\mathrm{Pt}(\mathrm{II})$ organometallic complexes bearing bidentate cyclometalating ligands and $\beta$-diketonate ancillary ligands, i.e., $\left(\mathrm{C}^{\wedge} \mathrm{N}\right) \mathrm{Pt}\left(\mathrm{O}^{\wedge} \mathrm{O}\right)$ and $\left(\mathrm{C}^{\wedge} \mathrm{C}\right) \mathrm{Pt}\left(\mathrm{O}^{\wedge} \mathrm{O}\right)$ derivatives (Figure 1). Following this introductory section, photophysical features of the $\mathrm{Pt}(\mathrm{II})$ complexes have been discussed. This is followed by application section in which we highlighted the organic photovoltaics (OPVs), organic light-emitting diodes (OLEDs), sensing, photocatalytic and other applications. Finally, concluding remarks are presented.

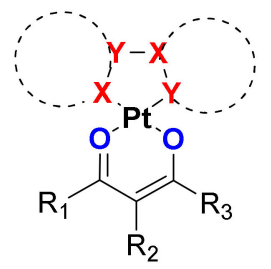

$$
\begin{aligned}
& \mathrm{X}, \mathrm{Y}=\mathrm{C}, \mathrm{C} \text { or } \mathrm{C}, \mathrm{N} \text { containing } \\
& \text { aromatic ring } \\
& R_{1}, R_{2} \& R_{3}=H \text {, alkyl, aryl or } \\
& \text { any other group }
\end{aligned}
$$

Figure 1. A general chemical structure of cyclometalated Pt(II) $\beta$-diketonate complexes covered in this review. Two aromatic rings (dotted lines) are joined through $\mathrm{C}-\mathrm{C}$ or $\mathrm{C}-\mathrm{N}$ bond.

\section{Structure-Property Relationships}

As stated before, the optical properties and applications of cyclometalated $\mathrm{Pt}(\mathrm{II})$ $\beta$-diketonates are sensitive to the electronic nature, steric effect, and rigidity of cyclometalating ligands and $\beta$-diketonates. Most, if not all, of their properties can be tuned through manipulation of the main and ancillary ligands [23-25]. Besides, square planar configuration of $\mathrm{Pt}(\mathrm{II})$ complexes assists in avoiding detrimental aggregation caused quenching (ACQ), which is one of the most prominent causes of emission loss in transition metal complexes [26]. In the subsections below, we discuss the effects of different cyclometalating and ancillary ligands on the optical properties of $\mathrm{Pt}(\mathrm{II})$ complexes. 


\section{1. $\left(\mathrm{C}^{\wedge} \mathrm{C}\right) \mathrm{Pt}\left(\mathrm{O}^{\wedge} \mathrm{O}\right)$ Type Complexes}

The last one-and-a-half decades witnessed a tremendous interest in the design and development of functional $\left(\mathrm{C}^{\wedge} \mathrm{C}\right) \mathrm{Pt}\left(\mathrm{O}^{\wedge} \mathrm{O}\right)$-type complexes [14]. Most of the square planar complexes were based on $\mathrm{N}$-heterocyclic carbene (NHC)-type cyclometalating ligands with $\beta$-diketonate derivatives. One of the main reasons behind selecting NHCs is their strong $\sigma$-donating tendency, high stability, and ability to tune the PL properties through structural modification. [27] Among NHCs, imidazole, pyrazole, and triazole-derivatives were the leading cores. Studies involving a variety of main and ancillary ligands show that there is no direct link between the optical properties and the substituents. The photophysical properties remain unchanged in some cases while they are enhanced in others. For example, complex 1 (Figure 2), based on imidazoe[1,5-a]pyridine-based Pt(II) complexes (1, Figure 2) with electron-withdrawing or donating moieties, did not show any significant effect of functional groups present over the cyclometalating/ancillary ligand on its PL properties [28]. However, a slight red-shifted absorption peak $(\sim 15 \mathrm{~nm})$ was reported for $\mathbf{1}\left(\mathrm{R}_{1}=\mathrm{OMe}\right.$, $\left.\mathrm{R}_{2}=\mathrm{H}, \mathrm{R}_{3}={ }^{t} \mathrm{Bu}, \mathrm{R}_{4}=\mathrm{C}_{6} \mathrm{H}_{5}\right)$, which can be attributed to the extended conjugation.

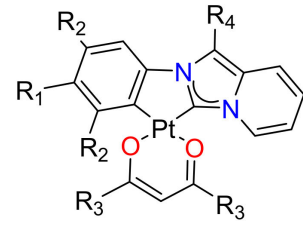

$\mathrm{R}_{1}=\mathrm{H}, \mathrm{OCH}_{3}, \mathrm{Br}$ or $\mathrm{CN}$

$\mathrm{R}_{2}=\mathrm{H}$ or $\mathrm{CF}_{3}$

$\mathrm{R}_{3}=\mathrm{Me}$ or ${ }^{{ }^{\mathrm{B}} \mathrm{Bu}}$

$\mathrm{R}_{4}=\mathrm{H}, \mathrm{C}_{6} \mathrm{H}_{5}$

(1)

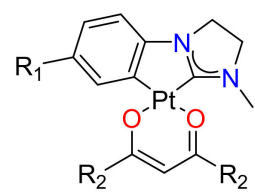

$\mathrm{R}_{1}=\mathrm{H}, \mathrm{Cl}, \mathrm{Me}$ $\mathrm{R}_{2}=\mathrm{Me}$, mes

(6)

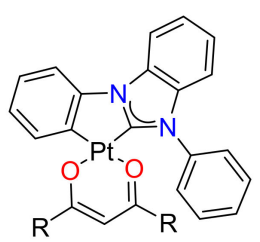

$\mathrm{R}=\mathrm{Me},{ }^{t} \mathrm{Bu}, \mathrm{C}_{6} \mathrm{H}_{5}$, mes, dur

(2)

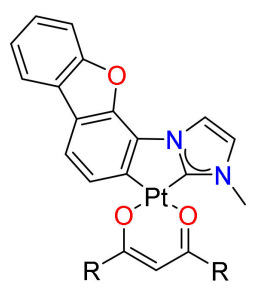

$\mathrm{R}=\mathrm{Me}, \mathrm{CF}_{3},{ }^{t} \mathrm{Bu}, \mathrm{C}_{6} \mathrm{H}_{5}$, mes

(3)

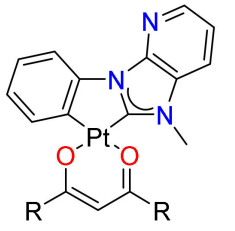

$\mathrm{R}=\mathrm{Me},{ }^{t} \mathrm{Bu}$, mes, dur

(4)

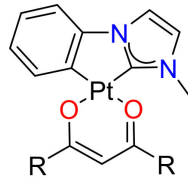

$\mathrm{R}=\mathrm{Me}$, mes, dur

(5)

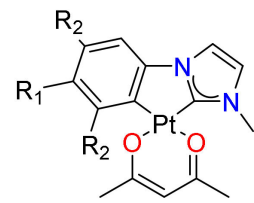

$\mathrm{R}_{1}=\mathrm{H}, \mathrm{CN}, \mathrm{CO}_{2} \mathrm{Et}$ $\mathrm{R}_{2}=\mathrm{H}, \mathrm{Cl}$

(7)

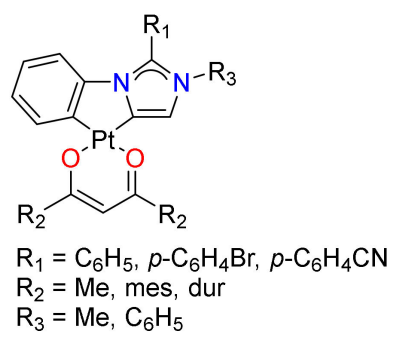

(8)

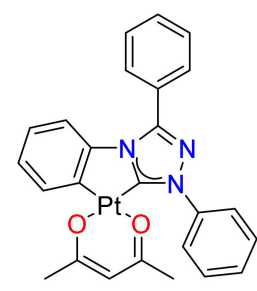

(9)

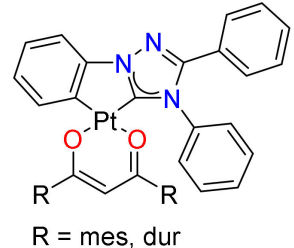

(10)

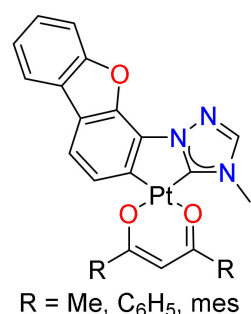

(11)

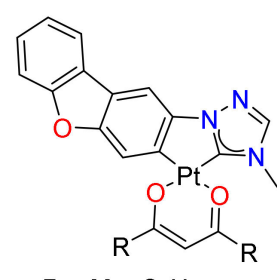

$\mathrm{R}=\mathrm{Me}, \mathrm{C}_{6} \mathrm{H}_{5}$, mes

(12)

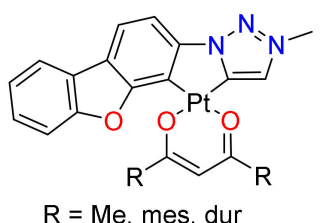

(13)

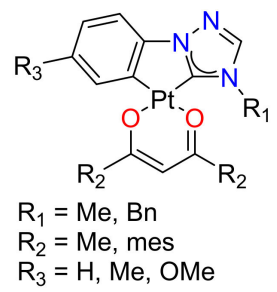

(14)

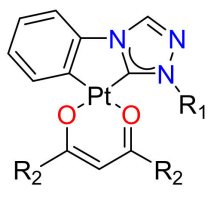

$\mathrm{R}_{1}=\mathrm{Me}, \mathrm{Bn}$

$\mathrm{R}_{2}=\mathrm{Me}$, mes

(15)

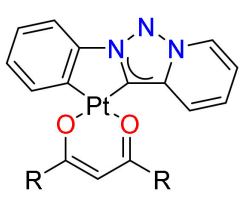

$R=M e$, mes, dur

(16)

Figure 2. $\mathrm{Pt}(\mathrm{II})$ complexes based on imidazole, pyrazole, and triazole-derivatives based NHCs as the cyclometalating ligand and $\beta$-diketonate derivatives as ancillary ligands.

On the other hand, researchers also noted that irrespective of the main ligand, ancillary ligand has a marked effect on the emission profile. For instance, when methyl $(\mathrm{R}=\mathrm{Me}$, $\lambda_{\mathrm{em}}=457 \mathrm{~nm}, \Phi=0.41, \tau_{0}=9.2 \mu \mathrm{s}$ in $2 \mathrm{wt} \%$ poly(methyl methacrylate) (PMMA)) group in complex 2 (Figure 2) is replaced by phenyl ring, the emission wavelength shifts to the red $\left(\lambda_{\mathrm{em}}=520 \mathrm{~nm}, \Phi=0.78, \tau_{0}=4.8 \mu \mathrm{s}\right.$ in $2 \mathrm{wt} \%$ PMMA) [29]. However, the presence of other aromatic systems ( $\mathrm{R}=$ mesityl (mes)/duryl (dur)) did not cause any significant shift. This unexpected behavior was attributed to the formation of more conjugated excited states in the case of the phenyl moiety, which can freely rotate [14]. There are also some 
examples where the emission is lost upon a slight change in the ancillary ligand. For example, replacing methyl $\left(\mathrm{R}=\mathrm{Me}, \lambda_{\mathrm{em}}=463,497 \mathrm{~nm}, \Phi=0.9, \tau_{0}=23 \mu \mathrm{s}\right.$ in $2 \mathrm{wt} \%$ PMMA) by trifluoromethyl $\left(\mathrm{CF}_{3}\right)$ group in complex 3 (Figure 2) was found to be detrimental for emission [30,31]. As noted in the previous example, and in this case as well, complexes containing phenyl and mes showed a red-shifted emission $\left(\lambda_{\mathrm{em}}=465 \mathrm{~nm}\right.$ for $\mathrm{R}={ }^{t} \mathrm{Bu} \rightarrow$ $\lambda_{\mathrm{em}}=530 \mathrm{~nm}$ for $\mathrm{R}=\mathrm{C}_{6} \mathrm{H}_{5}$, Table 1$)$ and improved $\Phi\left(\Phi=0.83\right.$ for $\mathrm{R}={ }^{t} \mathrm{Bu} \rightarrow \Phi=0.91$ for $\mathrm{R}=$ mes, Table 1 ), respectively.

Pinter et al. [32] studied the effect of introducing nitrogen into the backbone of the NHC and prepared a new class of compounds containing different auxiliary ligands (4, Figure 2). Interestingly, complexes containing the new heterocyclic ligand precursors presented an important influence on the emissive properties (Table 1) and aggregation behavior. In addition, the use of bulky ancillary ligand avoided molecular aggregation leading to excimeric emission. The combination of NHC containing pyridine heterocycle and bulky ancillary ligands allowed for remarkable emissive properties $(\Phi=0.91$ and 0.88 , for $\mathrm{R}=$ mes and dur, respectively) to be reached.

The photophysical analysis of 3-methyl-1-phenylimidazole-based complexes 5 (Figure 2) revealed that the $\Phi$ and $\tau_{0}$ values could be improved by introducing bulkier auxiliaries [17,31]. For example, it was noted that the introduction of mes or dur substituted $\beta$-diketonate [17] in $5(\mathrm{R}=\mathrm{Me})$ [31] led to a red shift of the emission band, $>10-12 \times$ increment in the $\Phi$ and decay times $\left(\tau_{0} \sim 3 \mu \mathrm{s}\right)$ (Table 1). To compare the effect of the saturated backbone of the NHC ligand on the photophysical properties, Stipurin and Strassner [11] reported Pt(II) complexes 6 (Figure 2) based on 1-aryl-3-methyl-imidazolinylidene ligands. These thermally stable complexes were found to absorb in the 280-450 nm region and emit between 470-490 $\mathrm{nm}$ with $\Phi=0.24-0.7$ and $\tau_{0}=5-25 \mu \mathrm{s}$. The wavelength maxima showed a slight dependency on the cyclometalating ligand. [11] Complex 7 (Figure 2) exhibits wavelength-dependent features with emission in the blue to green region of the visible spectrum when excited at $330 \mathrm{~nm}$ [33]. In such complexes, the presence of electronwithdrawing substituents in the 4-position of the cyclometalated ring confers very high $\Phi$ (Table 1). On the other hand, chloro-substituents at 3- and 5-positions of the cyclometalated ring have detrimental effect on the emission efficiency. The substitution effect was also observed on the formation of tellurium-based clusters. Electron-withdrawing substituents at 4-position favored the formation of the self-assembled 2D structure, whereas chlorosubstituents at the 3- and 5-positions leads to a discrete cluster. The inclusion of $\mathrm{Tl}(\mathrm{I})$ between the $\mathrm{Pt}(\mathrm{II})$ shows no beneficial effect on the $\Phi$ values [33].

There also exists a way of tuning the physical properties by changing the binding mode of NHC ligands. Inspired by their previous studies that highlighted the donor ability of using 1,2,3-triazol-5-ylidene, Strassner and coworkers [34] reported the first example of cyclometalated $\mathrm{Pt}(\mathrm{II})$ complexes with abnormal coordination mode of the main imidazolinylidene ligands (8, Figure 2). The reported complex showed ligand (cyclometalated and ancillary)-dependent absorption $\left(\lambda_{\mathrm{abs}}=225-450 \mathrm{~nm}\right.$ in DCM solution) and emissions $\left(\lambda_{\mathrm{em}}=523-585 \mathrm{~nm}\right.$ in $2 \mathrm{wt} \%$ in PMMA, Figure 3) profile with strong phosphorescence at room temperature and long-lived excited state. The emission was attributed to a strongly metal-perturbed intra-ligand/metal-to-ligand charge-transfer (ILCT/MLCT) process. 


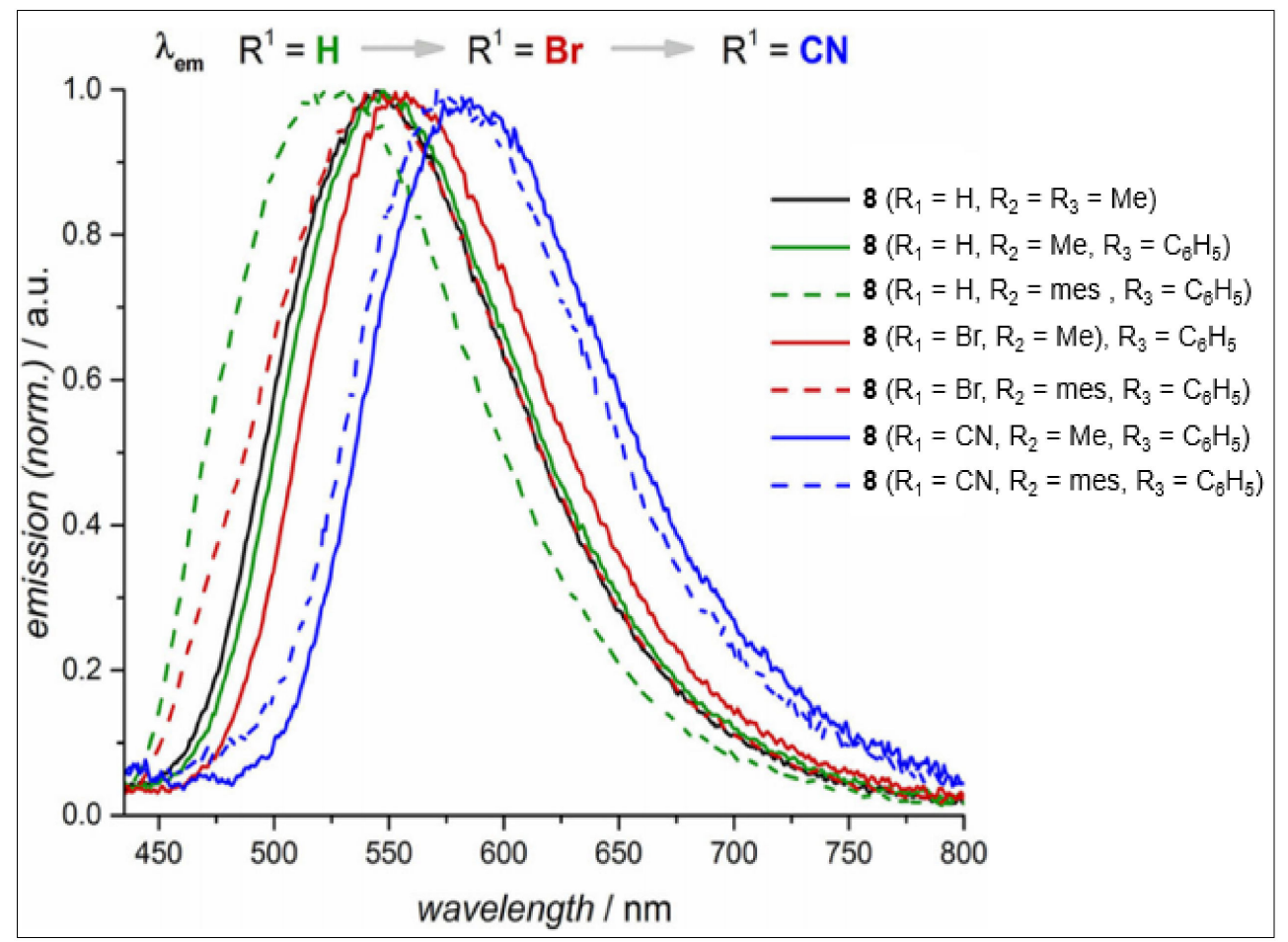

Figure 3. Emission spectra of complex 8 in PMMA matrix $\left(2 \mathrm{wt} \%\right.$ emitter load, $\left.\lambda_{\text {exc }}=360 \mathrm{~nm}\right)$ at room temperature. Reproduced with permission from ref. [34].

1,3,4-Triphenyl-1,2,4-triazole is a well-known ligand with mono-[35] and bidentate [36] coordination modes. It was found that the cyclometalated complex 9 (Figure 2) containing this ligand and acetylacetonate (acac) as an ancillary showed a phosphorescent emission with $\Phi=0.42$ and $\tau_{0}=35.6 \mu$ s (Table 1). On the other hand, structurally close analogue 10 (Figure 2) [37] with mes/dur unit showed higher values of $\Phi(2 \times)$ attributed to the steric protection in the excited state by the bulky $\beta$-diketonate ligands. Contrary to this study, when the $C$-donor (phenyl) was replaced by a dibenzo[b,d]furan-4-yl (DBF) moiety in $\mathrm{Pt}(\mathrm{II})$ complexes coordinated to 1,2,4-triazol-5-ylidene derivatives (11-12, Figure 2) [23], the PL properties showed dependency on both the DBF as well as the type of ancillary ligands. These complexes, which show multiple absorption peaks in the region of 250-390 nm, were blue-green emissions in the PMMA matrix $\left(\Phi=0.41-0.87\right.$ and $\left.\tau_{0}=6-26 \mu \mathrm{s}\right)$. Due to the differences in the arrangement of the DBF unit, complex $12(\mathrm{R}=\mathrm{Me}$, mes) had blue-shifted emission compared to $\mathbf{1 1}(\mathrm{R}=\mathrm{Me}$, mes). One of the complexes $(\mathbf{1 1}, \mathrm{R}=\mathrm{Me})$ also exhibited emission in neat film due to the formation of multimolecular complex while $12(\mathrm{R}=$ mes) showed emission due to monomeric species. This observation was attributed to the presence of a sterically demanding dimesitylmethanato ligand, which efficiently suppresses molecular stacking. On comparing 3 and $\mathbf{1 1}(\mathrm{R}=\mathrm{Me})$, which have different NHCs, we find somewhat different PL parameters, the former having higher $\Phi$ value but almost similar lifetimes (Table 1).

Very recently, using one of the DBF isomers, the same group prepared 1,2,3-triazolylidene ligand-based Pt(II) complexes (13, Figure 2) [38]. These compounds showed absorption in the UV region with onset of absorption at $\sim 425 \mathrm{~nm}$ and emission maxima $\sim 490 \mathrm{~nm}$ (Table 1). As expected, these complexes exhibit high $\Phi(0.67-0.78)$ and $\tau_{0}=17.7-20.5 \mu \mathrm{s}$ in the solid matrix than in the solution (Table 1). It was concluded that the ancillary ligand had no major effect on the emission and redox properties. 
Table 1. Photoluminescence data of some selected complexes (wt $\%$ in PMMA) at room temperature.

\begin{tabular}{|c|c|c|c|c|c|}
\hline Complex & $\lambda_{\text {exc }}$ & $\lambda_{\mathrm{em}}{ }^{\mathrm{c}}$ & $\Phi$ & $\begin{array}{c}\tau_{0} \\
(\mu s)\end{array}$ & Ref. \\
\hline $3\left(\mathrm{R}={ }^{t} \mathrm{Bu}\right)^{\mathrm{a}}$ & 355 & 465 & 0.83 & 27.4 & [30] \\
\hline $3\left(\mathrm{R}=\mathrm{C}_{6} \mathrm{H}_{5}\right)^{\mathrm{a}}$ & 370 & 530 & 0.51 & 4.7 & [30] \\
\hline $3(\mathrm{R}=\mathrm{mes})^{\mathrm{a}}$ & 335 & 466 & 0.91 & 18.9 & [30] \\
\hline $3(\mathrm{R}=\mathrm{Me})^{\mathrm{a}}$ & 355 & 463,497 & 0.90 & 23 & [31] \\
\hline $4(\mathrm{R}=\mathrm{Me})^{\mathrm{a}}$ & 340 & 458,547 & 0.64 & 4.8 & [32] \\
\hline $4\left(\mathrm{R}={ }^{t} \mathrm{Bu}\right)^{\mathrm{a}}$ & 340 & 456 & 0.74 & 5.8 & [32] \\
\hline $4(\mathrm{R}=\mathrm{mes})^{\mathrm{a}}$ & 340 & 472 & 0.91 & 2.9 & [32] \\
\hline $4(\mathrm{R}=\mathrm{dur})^{\mathrm{a}}$ & 355 & 466 & 0.88 & 3.3 & [32] \\
\hline $5(\mathrm{R}=\mathrm{Me})^{\mathrm{a}}$ & 320 & 441 & 0.07 & - & [31] \\
\hline $5\left(\mathrm{R}=\mathrm{mes}^{\mathrm{a}}\right.$ & 320 & 482 & 0.82 & 3.1 & [17] \\
\hline $5(\mathrm{R}=\text { dur })^{\mathrm{a}}$ & 320 & 479 & 0.72 & 3.3 & [17] \\
\hline $6\left(\mathrm{R}_{1}=\mathrm{H}, \mathrm{R}_{2}=\mathrm{Me}\right)^{\mathrm{a}}$ & 305 & 470 & 0.29 & 23 & [11] \\
\hline $6\left(\mathrm{R}_{1}=\mathrm{H}, \mathrm{R}_{2}=\mathrm{mes}\right)^{\mathrm{a}}$ & 305 & 486 & 0.71 & 5 & [11] \\
\hline $6\left(\mathrm{R}_{1}=\mathrm{Cl}, \mathrm{R}_{2}=\mathrm{Me}\right)^{\mathrm{a}}$ & 305 & 473 & 0.38 & 25 & [11] \\
\hline $6\left(\mathrm{R}_{1}=\mathrm{Cl}, \mathrm{R}_{2}=\mathrm{mes}^{\mathrm{a}}\right.$ & 305 & 476 & 0.7 & 7 & [11] \\
\hline $6\left(\mathrm{R}_{1}=\mathrm{Me}, \mathrm{R}_{2}=\mathrm{Me}\right)^{\mathrm{a}}$ & 305 & 481 & 0.24 & 23 & [11] \\
\hline $6\left(\mathrm{R}_{1}=\mathrm{Me}, \mathrm{R}_{2}=\mathrm{mes}\right)$ & 305 & 490 & 0.42 & 8 & [11] \\
\hline $7\left(\mathrm{R}_{1}=\mathrm{CN}, \mathrm{R}_{2}=\mathrm{H}\right)^{\mathrm{b}}$ & 330 & 470 & 0.98 & - & [33] \\
\hline $7\left(\mathrm{R}_{1}=\mathrm{COOEt}, \mathrm{R}_{2}=\mathrm{H}\right)^{\mathrm{b}}$ & 330 & 474 & 0.93 & - & [33] \\
\hline $7\left(\mathrm{R}_{1}=\mathrm{H}, \mathrm{R}_{2}=\mathrm{Cl}\right)^{\mathrm{b}}$ & 330 & 450 & 0.04 & - & [33] \\
\hline $9^{a}$ & 355 & 441,465 & 0.42 & 35.6 & [37] \\
\hline $10(\mathrm{R}=\mathrm{mes})^{\mathrm{a}}$ & 330 & 470 & 0.82 & 7.2 & [37] \\
\hline $10\left(\mathrm{R}=\right.$ dur $^{\mathrm{a}}$ & 330 & 467 & 0.87 & 8.5 & [37] \\
\hline $11(\mathrm{R}=\mathrm{Me})^{\mathrm{a}}$ & 370 & $474,506,542$ & 0.70 & 26 & [23] \\
\hline $11\left(\mathrm{R}=\mathrm{C}_{6} \mathrm{H}_{5}\right)^{\mathrm{a}}$ & 360 & 526 & 0.41 & 6 & [23] \\
\hline $11(\mathrm{R}=\mathrm{mes})^{\mathrm{a}}$ & 355 & $473,505,541$ & 0.76 & 26 & [23] \\
\hline $12(\mathrm{R}=\mathrm{Me})^{\mathrm{a}}$ & 330 & 446,474 & 0.71 & 24 & [23] \\
\hline $12\left(\mathrm{R}=\mathrm{C}_{6} \mathrm{H}_{5}\right)^{\mathrm{a}}$ & 370 & 524 & 0.45 & 7 & [23] \\
\hline $12\left(\mathrm{R}=\mathrm{mes}^{\mathrm{a}}\right.$ & 340 & 445,474 & 0.87 & 10 & [23] \\
\hline $13(\mathrm{R}=\mathrm{Me})^{\mathrm{a}}$ & 380 & 490 & 0.67 & 20.5 & [38] \\
\hline $13\left(\mathrm{R}=\mathrm{mes}^{\mathrm{a}}\right.$ & 380 & 488 & 0.69 & 17.9 & [38] \\
\hline $13(\mathrm{R}=\mathrm{Dur})^{\mathrm{a}}$ & 380 & 488 & 0.78 & 17.7 & [38] \\
\hline $14\left(\mathrm{R}_{1}=\mathrm{Bn}, \mathrm{R}_{2}=\mathrm{Me}, \mathrm{R}_{3}=\mathrm{H}\right)^{\mathrm{a}}$ & 330 & 432 & 0.13 & 15 & [39] \\
\hline $14\left(R_{1}=M e, R_{2}=\text { mes, } R_{3}=H\right)^{a}$ & 340 & 478 & 0.82 & 4 & [39] \\
\hline $14\left(\mathrm{R}_{1}=\mathrm{Me}, \mathrm{R}_{2}=\mathrm{mes}, \mathrm{R}_{3}=\mathrm{OMe}\right)^{\mathrm{a}}$ & 355 & 477 & 0.82 & 5 & [39] \\
\hline $14\left(R_{1}=M e, R_{2}=\text { mes, } R_{3}=M e\right)^{a}$ & 355 & 475 & 0.82 & 3 & [39] \\
\hline $14\left(R_{1}=B n, R_{2}=\text { mes, } R_{3}=H\right)^{a}$ & 370 & 477 & 0.72 & 5 & [39] \\
\hline $14\left(R_{1}=B n, R_{2}=\text { mes, } R_{3}=O M e\right)^{a}$ & 370 & 478 & 0.70 & 7 & [39] \\
\hline $14\left(R_{1}=B n, R_{2}=\text { mes, } R_{3}=M e\right)^{a}$ & 340 & 471 & 0.81 & 5 & [39] \\
\hline $15\left(\mathrm{R}_{1}=\mathrm{Bn}, \mathrm{R}_{2}=\mathrm{Me}\right)^{\mathrm{a}}$ & 330 & 455 & 0.35 & 15 & [39] \\
\hline $15\left(\mathrm{R}_{1}=\mathrm{Me}, \mathrm{R}_{2}=\mathrm{mes}\right)^{\mathrm{a}}$ & 345 & 477 & 0.82 & 4 & [39] \\
\hline $15\left(\mathrm{R}_{1}=\mathrm{Bn}, \mathrm{R}_{2}=\mathrm{mes}\right)^{\mathrm{a}}$ & 355 & 477 & 0.83 & 4 & [39] \\
\hline $16(\mathrm{R}=\mathrm{Me})^{\mathrm{a}}$ & 380 & 538 & 0.47 & 25.4 & [40] \\
\hline $16(\mathrm{R}=\mathrm{mes})^{\mathrm{a}}$ & 380 & 537 & 0.53 & 22 & [40] \\
\hline $16(\mathrm{R}=\mathrm{dur})^{\mathrm{a}}$ & 380 & 537 & 0.54 & 22.6 & [40] \\
\hline
\end{tabular}

$\mathrm{a}=2 \mathrm{wt} \%,{ }^{\mathrm{b}}=5 \mathrm{wt}^{\mathrm{m}},^{\mathrm{c}}=$ Wavelength at the emission maximum.

Another study revealed that the emission behavior of $\mathrm{Pt}(\mathrm{II})$ complexes is independent of the position of the $N$ atom in the backbone of the NHC unit but depends on the auxiliary ligand $\left(\mathrm{O}^{\wedge} \mathrm{O}\right)$. A comparative study of $\mathrm{Pt}(\mathrm{II})$ complexes possessing 1-phenyl-1,2,4triazol-5-ylidene or 4-phenyl-1,2,4-triazol-5-ylidene as $\mathrm{C}^{\wedge} \mathrm{C}$ ligand and acac or 1,3-bis(2,4,6trimethylphenyl)propan-1,3-dionato (mesacac) as ancillary ligands (14-15, Figure 2) was carried out by Strassner and coworkers [39]. It was reported that the complexes show very weak emissions in solution but are strongly emissive $\left(\lambda_{\mathrm{em}}=432-478 \mathrm{~nm}\right)$ with high quantum efficiencies $(\Phi=0.13-0.82)$ and short decay times $\left(\tau_{0}=3-15 \mu \mathrm{s}\right)$ with mesityl substituted derivative (mesacac) ancillary ligands in PMMA matrix (Table 1). To underpin 
whether the extension of a conjugated system or annulation to the NHC ligand has a pronounced effect on the optical properties, cyclometalated $\mathrm{Pt}(\mathrm{II})$ complexes with annulated 1,2,3-triazolylidene-based ligand (16, Figure 2) have been reported [40]. The emission properties of these complexes were nearly similar at room temperature with emissions in the yellow region (537-539 nm) with $\Phi=0.47-0.54$ (Table 1 ). The use of sterically demanding $\beta$-diketonate ligands led to slightly increased efficiencies compared to the parent acac complex.

Among the N-containing NHC donors, thiazole as C-cyclometalating unit has also been tested. To determine the impact of electronic effect, 4- and/or 5-position of the 1,3thiazole moiety as well as $N$-aryl moiety were substituted [41,42]. Complexes $\mathbf{1 7}\left(\mathrm{R}_{1}=\mathrm{Me}\right.$, $\mathrm{C}_{6} \mathrm{H}_{5}, \mathrm{C}_{4} \mathrm{H}_{4} ; \mathrm{R}_{2}=\mathrm{H}, \mathrm{COOMe}, \mathrm{Me}, \mathrm{C}_{6} \mathrm{H}_{5}, \mathrm{C}_{4} \mathrm{H}_{4} ; \mathrm{R}_{3}=\mathrm{Me} ; \mathrm{R}_{4}=\mathrm{R}_{5}=\mathrm{R}_{6}=\mathrm{H}$, Figure 4) with functionalized thiazole ring (different substituents in the 4- and 5-position of the thiazole heterocycle) showed broad absorption peaks at around $\sim 275,300$ and $360 \mathrm{~nm}$ and bluish-green phosphorescence (497-522 nm) at room temperature in $2 \mathrm{wt} \%$ PMMA. The emission in such complexes was suggested to be ${ }^{3} \mathrm{MLCT} /{ }^{3} \mathrm{ILCT}$ admix nature. It is interesting to note that the absorption intensity, wavelength, quantum yields, and decay lifetimes did show variation with the inductive and mesomeric effects of the substituents over thiazole moiety; however, the maximum emission wavelength was found to be almost independent. Overall, the presence of methyl and ester groups was beneficial in terms of $\Phi$ and $\tau_{0}$.

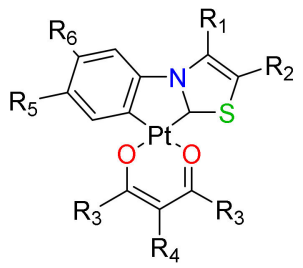

$\mathrm{R}_{1}=\mathrm{H}, \mathrm{Me}, \mathrm{C}_{6} \mathrm{H}_{5},\left(\mathrm{C}_{4} \mathrm{H}_{4}\right)$

$\mathrm{R}_{2}=\mathrm{H}, \mathrm{CO}_{2} \mathrm{Me}, \mathrm{Me}, \mathrm{C}_{6} \mathrm{H}_{5},\left(\mathrm{C}_{4} \mathrm{H}_{4}\right)$

$\mathrm{R}_{3}=\mathrm{Me}, \mathrm{CF}_{3}, \mathrm{tBu}, \mathrm{C}_{6} \mathrm{H}_{5}$, mes, dur

$\mathrm{R}_{4}=\mathrm{H}, \mathrm{Me}, \mathrm{C}_{6} \mathrm{H}_{5}$

$\mathrm{R}_{5}=\mathrm{H}, \mathrm{Br}, \mathrm{OMe}, \mathrm{CN}, \mathrm{Me}, \mathrm{COOMe}$

$\mathrm{R}_{6}=\mathrm{H}, \mathrm{Me}$

(17)

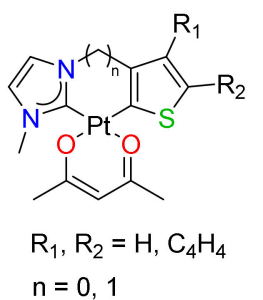

(18)

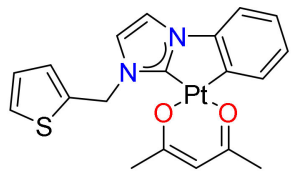

(19)

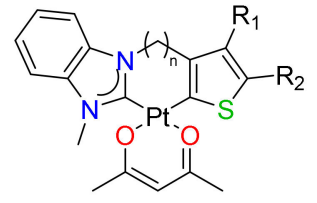

$\mathrm{R}_{1}, \mathrm{R}_{2}=\mathrm{H}, \mathrm{C}_{4} \mathrm{H}_{4}$

$\mathrm{n}=0,1$

(20)

Figure 4. $\mathrm{Pt}(\mathrm{II})$ complexes based on thiazole-derived NHCs as the cyclometalating ligand and $\beta$-diketonate derivatives as ancillary ligands.

On the other hand, when substituents on the $N$-phenyl ring were modified $\left(\mathbf{1 7}, \mathrm{R}_{1}=\mathrm{R}_{2}\right.$ $=\mathrm{R}_{3}=\mathrm{R}_{4}=\mathrm{Me} ; \mathrm{R}_{5}=\mathrm{H}, \mathrm{Br}, \mathrm{OMe}, \mathrm{CN}, \mathrm{Me}, \mathrm{COOMe} ; \mathrm{R}_{6}=\mathrm{H}, \mathrm{Me}$, Figure 4) [42], a strong absorption between $250-280 \mathrm{~nm}$ was observed with some additional peaks $\sim 360-370 \mathrm{~nm}$. The PL study revealed that all complexes emit in a very narrow range (508-526 nm; blue-green) with high $\Phi(0.33-0.79)$ and $\tau_{0}(8.1-21.4 \mu \mathrm{s})$ values. The emission wavelength maximum was almost independent of electron-donating or electron-withdrawing groups at the cyclometalating aryl ring. However, different shapes of the emission spectra were indicative of different underlying emission processes. Like the previous example, the presence of the ester group over the phenyl ring was beneficial as complex $17\left(R_{1}=R_{2}=R_{3}=M e\right.$; $\mathrm{R}_{4}=\mathrm{R}_{6}=\mathrm{H} ; \mathrm{R}_{5}=$ COOMe, Figure 4$)$ showed high $\Phi\left(0.79\right.$ in $2 \mathrm{wt} \%$ PMMA) and low $\tau_{0}$ $(8.11 \mu$ s in $2 \mathrm{wt} \%$ PMMA), which retained high $\Phi(0.68$ in the $100 \%)$ in film.

Another study reflected the effect of variation of auxiliary ligand on PL properties. Except for complex 17, which beared an electron-withdrawing substituent $\left(\mathrm{R}_{1}=\mathrm{R}_{2}=\mathrm{Me}\right.$; $\left.\mathrm{R}_{3}=\mathrm{CF}_{3} ; \mathrm{R}_{4}=\mathrm{R}_{5}=\mathrm{R}_{6}=\mathrm{H}, \Phi=0.01\right)$, all other complexes $\left(\mathrm{R}_{1}=\mathrm{R}_{2}=\mathrm{Me} ; \mathrm{R}_{3}=\mathrm{Me},{ }^{t} \mathrm{Bu}\right.$, $\mathrm{C}_{6} \mathrm{H}_{5}$, mes, dur; $\mathrm{R}_{4}=\mathrm{Me}, \mathrm{C}_{6} \mathrm{H}_{5} ; \mathrm{R}_{5}=\mathrm{R}_{6}=\mathrm{H}$, Figure 4) emitted in the green to yellow region (508-526 nm) with high $\Phi(0.17-0.66)$ and low $\tau_{0}(5.4-13.7 \mu \mathrm{s})$ in $2 \mathrm{wt} \%$ PMMA) [18]. In these complexes too, the emission maxima were independent of the $\beta$-diketonate ligand. Anderson and coworkers [43] reported a comparative analysis of five- and six-membered $\mathrm{Pt}$ (II) complexes 18-20 (Figure 4) based on thiophene (Th) / benzothiophene (Bth) cores. 
The reported complex exhibited absorption in the 325-450 $\mathrm{nm}$ region and emission bands within the $430-530 \mathrm{~nm}$ region from a ${ }^{3} \mathrm{MLCT}$ excited state. Whereas imidazole-containing complexes display a broad monomeric emission, benzimidazole showed two bands due to excimeric emission. In addition, complexes 18 and 19 had lifetimes between 241-959 $\mu$ s, while 20 had 350-989 $\mu \mathrm{s}$. When compared between 5/6-membered metallacycles, it was noted that the Bth-containing complexes displayed a lower magnitude red-shifted emission band compared to their Th-containing analogues. The opposite effect is noted in the fivemembered metallacycles, where the benzothiophene-containing analogues displayed a greater, red-shifted emission band compared to their thiophene-containing analogues.

\section{2. $\left(\mathrm{C}^{\wedge} \mathrm{N}\right) \mathrm{Pt}\left(\mathrm{O}^{\wedge} \mathrm{O}\right)$ Type Complexes}

Compared to $\mathrm{C}^{\wedge} \mathrm{C}^{*}$ cyclometalated $\mathrm{Pt}(\mathrm{II})$ complexes, the $\mathrm{C}^{\wedge} \mathrm{N}$ analogues exhibit a wider range of properties/applications. Various complexes of the type $\left(\mathrm{C}^{\wedge} \mathrm{N}\right) \mathrm{Pt}\left(\mathrm{O}^{\wedge} \mathrm{O}\right)$ featuring 2-phenylpyridine (2-ppy), 2-thienylpyridine, 2-phenylbenimidazole, etc. cyclometalating ligands supported by diketonate derivatives have been assessed recently. A minor change in the functional group or position has a remarkable effect on their PL properties [44]. It has been demonstrated that the topology/connectivity of metal to ligand influences the photophysical properties, and this has been exploited to realize long-lived ${ }^{3} \mathrm{IL}$ or dual (fluorescence and phosphorescence) emission [45,46] and charge transfer (CT) [47]. Fluorinated substituents are well known for altering the electron distribution and providing steric protection around the metal center. The installation of a strong acceptor $-\mathrm{CF}_{3}$ on the cyclometalated 2-ppy at the 5-position of the pyridine ring resulted in a red shift of the emission compared to complex based on nonfunctionalized 2-ppy [48]. In the literature, most of the bidentate $\mathrm{C}^{\wedge} \mathrm{N}$ main ligands are based on 2-ppy derivatives as they can be easily functionalized to target desired properties. Zhong and coworkers [49,50] demonstrated that a minor variation in the ppy core affects the molecular packing and emission properties. They introduced one or two fluorine substituents in the ppy core to realize complex 21 $\left(\mathrm{R}_{1}=\mathrm{R}_{2}=\mathrm{C}_{6} \mathrm{H}_{5} ; \mathrm{R}_{3}=\mathrm{Me} ; \mathrm{R}_{4}=\mathrm{R}_{5}=\mathrm{R}_{6}=\mathrm{H}, \mathrm{F}\right.$, Figure 5) having a similar emission profile in solution but was different (green to orange) in the solid state.

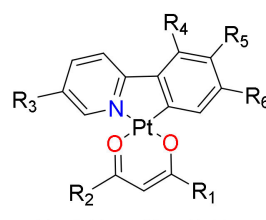

$\mathrm{R}_{1} \& \mathrm{R}_{2}=\mathrm{Me}, \mathrm{C}_{6} \mathrm{H}_{5}$

$\mathrm{R}_{3}=\mathrm{H}, \mathrm{Me}$

$\mathrm{R}_{4}=\mathrm{H}, \mathrm{F}$

$\mathrm{R}_{5}=\mathrm{H}, \mathrm{F}, 4-\mathrm{C}_{6} \mathrm{H}_{4} \mathrm{~F}, 3,4-\mathrm{C}_{6} \mathrm{H}_{3} \mathrm{~F}_{2}, 3,4,5-\mathrm{C}_{6} \mathrm{H}_{2} \mathrm{~F}_{3}$

$\mathrm{R}_{6}=\mathrm{H}, \mathrm{F}, \mathrm{C}_{6} \mathrm{H}_{5}, 4-\mathrm{C}_{6} \mathrm{H}_{4} \mathrm{~F}, 2,4-\mathrm{C}_{6} \mathrm{H}_{3} \mathrm{~F}_{2}, 3,4-\mathrm{C}_{6} \mathrm{H}_{3} \mathrm{~F}_{2}, 3,4,5-\mathrm{C}_{6} \mathrm{H}_{2} \mathrm{~F}_{3} \mathrm{R}_{1}, \mathrm{R}_{2}=\mathrm{H}, \mathrm{F}$

(21)

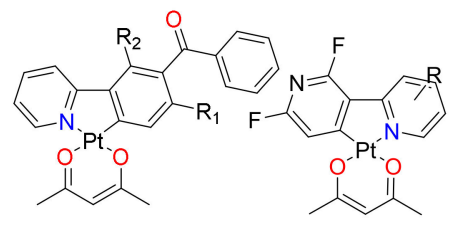

(22)
$\mathrm{R}=$ none, 4-TMS, 5-TMS

(23)

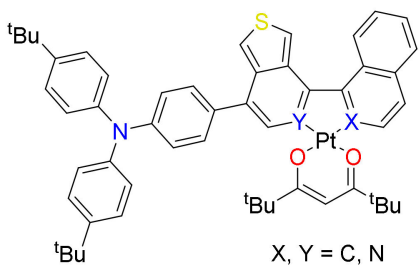

(24)

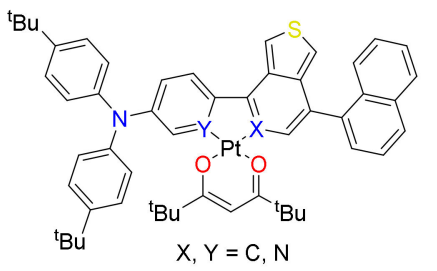

(25)

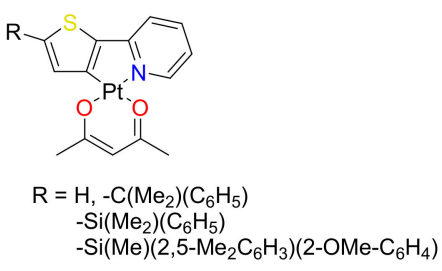

(26)

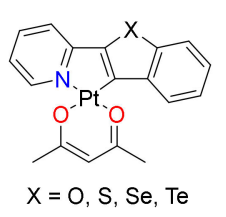

(27)

Figure 5. $\mathrm{Pt}(\mathrm{II})$ complexes based on 2-phenylpyridine, 2-thienylpyridine, 2-phenylbenzimidazole, etc. cyclometalating ligands and $\beta$-diketonate derivatives as ancillary ligands.

All complexes showed an admix of LLCT and MLCT transitions in the region of $330 \mathrm{~nm}$ to $450 \mathrm{~nm}$ [49]. However, the maximum emission wavelengths were the same for all complexes in solution, $\Phi$ and $\tau$ varied according to the number of F-atoms. In 
general, complex $21\left(\mathrm{R}_{1}=\mathrm{R}_{2}=\mathrm{C}_{6} \mathrm{H}_{5} ; \mathrm{R}_{3}=\mathrm{Me} ; \mathrm{R}_{4}=\mathrm{R}_{6}=\mathrm{F} ; \mathrm{R}_{5}=\mathrm{H}\right.$, Figure 5) having two $\mathrm{F}$ atoms showed higher $\tau(1.02 \mu \mathrm{s})$ and $\Phi(0.16)$ values in solution. Moreover, microcrystals demonstrated different luminescence properties than macro/large crystals (Figure 6). Microcrystalline emission (up to $\Phi=0.51$ ) was also reported in 2-phenylbenzimidazolebased $\mathrm{Pt}(\mathrm{II})$ complexes bearing acac ancillaries [26].
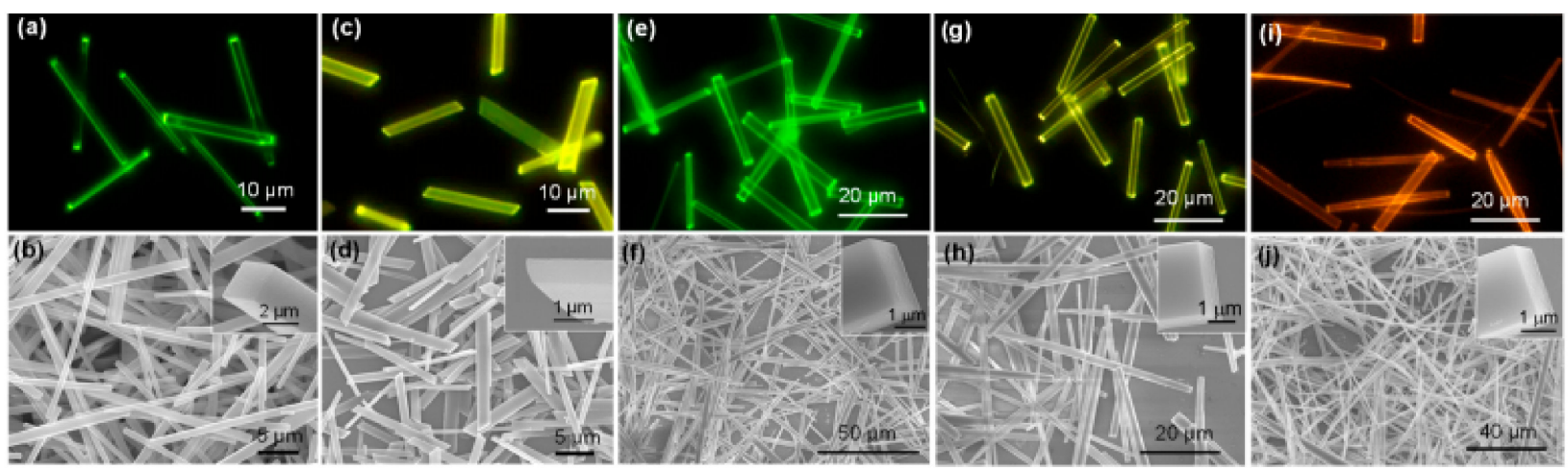

Figure 6. (a,c,e,g,i) Fluorescence microscopy images and (b,d,f,h, $\mathbf{j})$ SEM images of microcrystals of $(\mathbf{a}, \mathbf{b}) \mathbf{2 1}-\mathbf{g}\left(\mathrm{R}_{1}=\mathrm{R}_{2}=\mathrm{C}_{6} \mathrm{H}_{5}\right.$; $\left.\mathrm{R}_{3}=\mathrm{Me} ; \mathrm{R}_{4}=\mathrm{R}_{6}=\mathrm{F} ; \mathrm{R}_{5}=\mathrm{H}\right)(\mathbf{c}, \mathbf{d}) \mathbf{2 1}-\mathrm{y}\left(\mathrm{R}_{1}=\mathrm{R}_{2}=\mathrm{C}_{6} \mathrm{H}_{5} ; \mathrm{R}_{3}=\mathrm{Me} ; \mathrm{R}_{4}=\mathrm{R}_{6}=\mathrm{F} ; \mathrm{R}_{5}=\mathrm{H}\right)(\mathbf{e}, \mathbf{f}) 21\left(\mathrm{R}_{1}=\mathrm{R}_{2}=\mathrm{C}_{6} \mathrm{H}_{5} ; \mathrm{R}_{3}=\mathrm{Me} ;\right.$ $\left.\mathrm{R}_{4}=\mathrm{F} ; \mathrm{R}_{5}=\mathrm{R}_{6}=\mathrm{H}\right),(\mathrm{g}, \mathrm{h}) 21\left(\mathrm{R}_{1}=\mathrm{R}_{2}=\mathrm{C}_{6} \mathrm{H}_{5} ; \mathrm{R}_{3}=\mathrm{Me} ; \mathrm{R}_{4}=\mathrm{R}_{6}=\mathrm{H} ; \mathrm{R}_{5}=\mathrm{F}\right.$, and $(\mathbf{i}, \mathbf{j}) 21\left(\mathrm{R}_{1}=\mathrm{R}_{2}=\mathrm{C}_{6} \mathrm{H}_{5} ; \mathrm{R}_{3}=\mathrm{Me} ;\right.$ $\left.\mathrm{R}_{4}=\mathrm{R}_{5}=\mathrm{H} ; \mathrm{R}_{6}=\mathrm{F}\right)$. The inset shows enlarged SEM images of the ends of microrods. Reproduced with permission from ref. [49].

Several researchers kept the acac as ancillary ligand and functionalized the main ligand to study both the electronic and steric effects. Bearing this in mind and to underpin how the position of a fluorophenyl substituent affects the structural, photophysical properties and applications (oxygen sensing), Xing et al. [51] reported complex $21\left(\mathrm{R}_{1}=\mathrm{R}_{2}=\mathrm{Me}\right.$; $\mathrm{R}_{3}=\mathrm{R}_{4}=\mathrm{H} ; \mathrm{R}_{5}, \mathrm{R}_{6}=4-\mathrm{C}_{6} \mathrm{H}_{4} \mathrm{~F}, 3,4-\mathrm{C}_{6} \mathrm{H}_{3} \mathrm{~F}_{2}, 3,4,5-\mathrm{C}_{6} \mathrm{H}_{2} \mathrm{~F}_{3}$, Figure 5) containing 2-ppy with a fluorophenyl substituent at the para or meta position of the phenyl ring. As observed in similar complexes, the reported fluorophenyl containing complexes showed no metallophilic (Pt..Pt) interaction in the solid state. Moreover, compared to the parent complex $\mathrm{Pt}(\mathrm{ppy})(\mathrm{acac})$, both meta and para complexes showed red-shifted absorption and emission maxima $\left(\lambda_{\mathrm{Pt}(\mathrm{ppy})(\mathrm{acac})}<\lambda_{\text {meta }}\right.$ complexes $<\lambda_{\text {para }}$ complexes $)$. This can be attributed to the presence of strong electron-withdrawing fluorine substituents, which lowers the energy level of frontier molecular orbitals. Moreover, a noticeable difference was also found in the $\tau_{0}(1.39-4.11 \mu \mathrm{s}$ for para and 1.03-2.23 $\mu \mathrm{s}$ for meta) and $\Phi$ values $(0.15-0.22$ for para and $0.14-0.22$ for meta). It was noted that compared to $\operatorname{Pt}(\mathrm{ppy})(\mathrm{acac})\left(\tau_{0}=2.6 \mu \mathrm{s}\right)$, the lifetime value reduced when the number of fluorine atom increases (except for para). The role of fluorine, phenyl, and 2,4-difluorophenyl substituents $21\left(\mathrm{R}_{1}=\mathrm{R}_{2}=\mathrm{Me} ; \mathrm{R}_{3}=\mathrm{R}_{5}=\mathrm{H}\right.$; $\mathrm{R}_{4}=\mathrm{H}, \mathrm{F} ; \mathrm{R}_{6}=\mathrm{F}, \mathrm{C}_{6} \mathrm{H}_{5}, 2,4-\mathrm{C}_{6} \mathrm{H}_{3} \mathrm{~F}_{2}$, Figure 5) on the photophysical and sensing properties were also studied by Liu and coworkers [52] These complexes also showed very similar photophysical data to earlier discussed complexes. For instance, emission maxima between $467-526 \mathrm{~nm}, \tau_{0}=1.24-4.56 \mu$ s and $\Phi=0.04-0.24$ was noted for the complexes. Complexes bearing phenyl or fluorophenyl substituents showed red shifted emission and higher quantum yield compared to the $\mathrm{Pt}(\mathrm{ppy})(\mathrm{acac})$ and other fluorinated complexes. Considering the properties and features of such complexes, it can be concluded that changing the substituent/topology (connectivity) affects the electronic distribution leading to the change in photophysical properties. Okamura et al. [53] reported the properties and OLED application of Pt(II) complexes bearing $5^{\prime}$-benzoylated 2-ppy ligands with or without fluorine substituent(s) 22 (Figure 5). The combination of benzoyl and fluorine substituents had a noticeable impact on the $\tau_{0}(0.3-1.37 \mu \mathrm{s}), \Phi(0.06-0.28)$ and emission spectra $(465-479 \mathrm{~nm}$ and $497-513 \mathrm{~nm}$ in solution). In addition, the presence of fluorine and carbonyl groups led to enhanced excimeric emission. As noted earlier, $\Phi$ value varies inversely with the 
number of fluorine atoms. It was suggested that the electronic effect of the carbonyl was the main role-player rather than $\pi$-extension factor.

The modulation of luminescence properties exploiting NCI in organic systems is an intriguing strategy. However, such observation is limited to organometallic systems. An account of modulated PL properties and application via intermolecular interactions can be found in a recent review by Klein and coworkers [13]. Kang et al. [54] noted that the introduction of a bulky trimethylsilyl (TMS) group at the 4- or 5 positions of the $\mathrm{N}$-donating pyridine ring $\mathbf{2 3}$ (Figure 5) is an effective strategy to endow intermolecular interaction and modulate structural as well as photophysical properties. For example, it was noted that the complex 23 ( $\mathrm{R}=$ none) forms stacked dimer via $\mathrm{Pt}(\mathrm{II}) \cdots \pi$ interactions while complexes 23 ( $R=4 / 5$-TMS) prefer dimeric structure supported by Pt $\cdots \mathrm{Pt}$ and $\pi-\pi$ interactions (Figure 7). Complexes containing TMS exhibit red-shifted absorption and emission profiles than the one without TMS. A comparison of the frontier molecular orbital energy level indicated that the introduction of a TMS group lowered the HOMO level (with little impact on LUMO level) and increased the energy gap (Eg) compared to $\mathrm{Pt}(\mathrm{ppy})(\mathrm{acac})$ and other related fluorinated systems. The presence of strong intermolecular interaction also improved the quantum yield ( $\Phi=0.44$ for $23(R=$ none) and $0.60-0.65$ for 23 ( $\mathrm{R}=4 / 5$-TMS) in DCM solution) of the complexes and assisted in excimeric emission. Kukushkin and coworkers [55] adopted another strategy to enhance the luminescence properties. They found that the 1:1 co-crystal prepared using $\pi$ hole-donating electrondeficient arene systems (viz. perfluorinated arenes) and $\mathrm{Pt}(\mathrm{II})$ complex such as $\mathrm{Pt}(\mathrm{ppy})(\mathrm{acac})$ or $\mathrm{Pt}(\mathrm{pbz})(\mathrm{acac})$ (where $\mathrm{pbz}=2$-phenylbenzothiazole) exhibit $\pi$-hole $\cdots \mathrm{dz}^{2}\left(\mathrm{Pt}^{\mathrm{II}}\right)$ interactions . Owing to such interactions, enhanced phosphorescence was reported in the solid states. For example, $\mathrm{Pt}(\mathrm{ppy})(\mathrm{acac})$ and octafluoronaphthalene exhibit much better PL properties $\left(\Phi=0.11, \tau_{0}=8.42 \mu \mathrm{s}\right)$ than the $\mathrm{Pt}(\mathrm{II})$ complex alone $\left(\Phi=0.03, \tau_{0}=0.58 \mu \mathrm{s}\right)$ in the solid state. Overall, the work opens up a new dimension for tuning the PL properties via altering supramolecular properties.

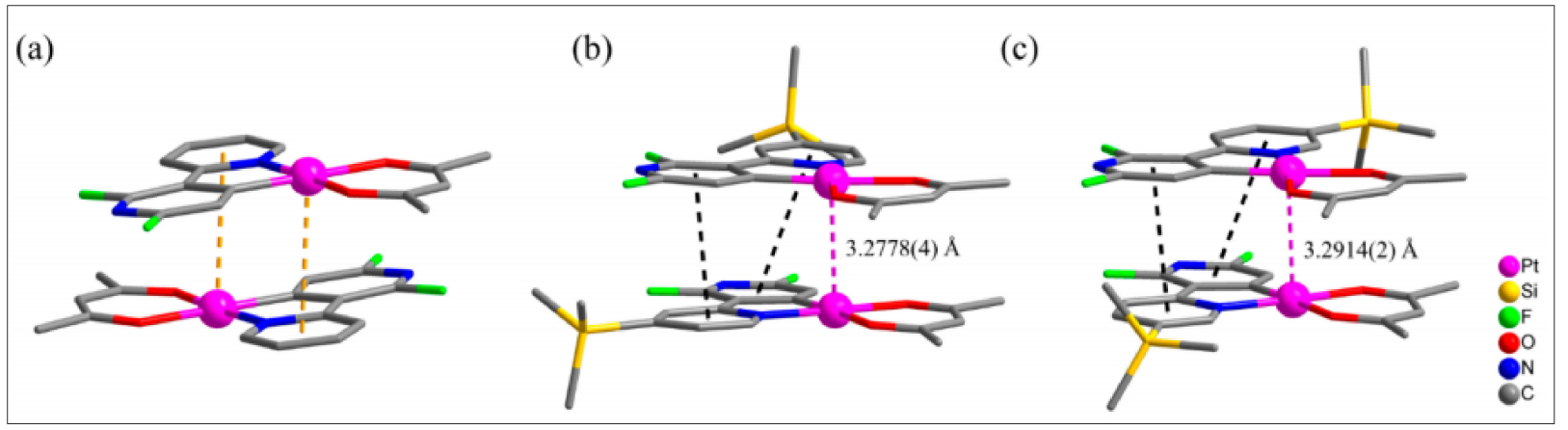

Figure 7. Dimeric structures of complexes 23 ( $\mathrm{R}=$ none, 4/5-TMS) formed via Pt $\cdots \pi$ (yellow-dashed lines), $\pi-\pi$ (blackdashed lines), and Pt...Pt (violet-dashed lines) interactions. H atoms were omitted for clarity. (a) $R=$ none; (b) $R=4$-TMS and (c) $\mathrm{R}=5$-TMS. Reproduced with permission from ref. [54].

Among various molecular engineering strategies [6,7], one established way is to create an intramolecular donor-acceptor (D-A)-type interaction. Such interaction is often used to achieve low Eg materials with near infra-red absorption/emission features. Wong and coworkers [56] found that the D-A interaction can be achieved via adjusting coordination position with isomeric ligands. Isomeric complexes 24 and $25(\mathrm{X}, \mathrm{Y}=\mathrm{C} / \mathrm{N}$, Figure 5) displayed excellent thermal stability, photophysical $\left(\mathrm{E}_{g, \text { film }}^{o p .}=1.72-2.23 \mathrm{eV}\right.$ with $\lambda_{\text {onset }}^{\text {film }}=556-720 \mathrm{~nm}, \lambda_{\text {em }}^{\text {sol }}=590-761 \mathrm{~nm}, \tau_{0}=0.11-1.09 \mu$ s and $\left.\Phi=0.6-2.2\right)$, electrochemical $\left(\mathrm{E}_{o x .}^{1 / 2}=0.86-1.01 \mathrm{~V} \mathrm{vs} \mathrm{Ag} / \mathrm{AgCl}\right.$ ), and electroluminescent (EL peaks between $626-826 \mathrm{~nm}$ and $\mathrm{EQE}=0.04-0.49 \%$ ) properties.

Usuki and coworkers [57] reported a comparative property of complexes 26 (Figure 5). Due to the presence of bulky side chains (which reduced $\pi-\pi$ interactions) complexes 26 $\left(\mathrm{R}=-\mathrm{C}\left(\mathrm{Me}_{2}\right)\left(\mathrm{C}_{6} \mathrm{H}_{5}\right),-\mathrm{Si}\left(\mathrm{Me}_{2}\right)\left(\mathrm{C}_{6} \mathrm{H}_{5}\right),-\mathrm{Si}(\mathrm{Me})\left(2,5-\mathrm{Me}_{2} \mathrm{C}_{6} \mathrm{H}_{3}\right)\left(2-\mathrm{OMe}-\mathrm{C}_{6} \mathrm{H}_{4}\right)\right.$ exhibit unique 
emission features in the solid and solution states. For instance, $26(R=H)$ showed weak emission in the solid state (due to $\pi-\pi$ stacking in the solid state), while other complexes exhibited bright luminescence in the solid state with good emission efficiency $\left(\Phi_{\mathrm{P}}=0.33-0.49\right.$, $\left.\tau_{0}=1.80-14.6 \mu \mathrm{s}\right)$. Overall, this work demonstrated that the introduction of a side chain containing quaternary carbon or silicon atoms into the $\mathrm{Pt}(\mathrm{thpy})$ (acac) skeleton promoted solid-state emission without impairing either the emission efficiency or color. To study the effect of the inclusion of chalcogenides (O, S, Se, Te) in $\mathrm{Pt}(\mathrm{II})$ complexes, $\mathrm{Wu}$ and coworkers [58] reported complexes 27 (Figure 5). These complexes exhibit an intense $\pi \rightarrow \pi^{*}$ band below $400 \mathrm{~nm}$ and a low energy weak band of singlet and triplet CT nature in the visible. It was noted that instead of a variation of absorption and emission wavelengths in the order $\mathrm{O} \rightarrow \mathrm{S} \rightarrow \mathrm{Se} \rightarrow \mathrm{Te}$ (due to enhanced electron-donating ability), S-containing complex showed some deviation. For instance, $27(X=S)\left(\lambda_{\mathrm{em}}=611 \mathrm{~nm}\right.$ and $\left.664 \mathrm{~nm}\right)$ showed blue-shifted emission peaks as $27(X=0)\left(\lambda_{\text {em }}=616 \mathrm{~nm} \& 674 \mathrm{~nm}\right), 27(X=$ Se $)\left(\lambda_{\text {em }}=621\right.$ and $674 \mathrm{~nm})$ and $27(X=\mathrm{Te})\left(\lambda_{\mathrm{em}}=634 \mathrm{~nm}\right.$ and $\left.690 \mathrm{~nm}\right)$. High aromaticity of the Th ring was suggested as the major factor behind this observation.

In addition to the above-mentioned mononuclear complexes, some excellent di- and trinuclear cyclometalated $\mathrm{Pt}(\mathrm{II})$ complexes have also been reported in recent times. This includes bimetallic complexes (homo-/hetero-multi-nuclear metal complexes) with unique bridging ligands [59]. Figure 8 illustrates some examples of homo- and heterobimetallic complexes reported recently, while Table 2 depicts the absorption and emission profile of some selected mono- and bimetallic $\mathrm{Pt}(\mathrm{II})$ cyclometalated complexes. The inclusion of the second metal atom not only enhances the SOC and adjusts the emissive triplet states, but also improves their properties and performance [16]. For example, complex 28 (Figure 8) showed a dual phosphorescence emissive character at room-temperature with increased $\Phi$ compared to that of its monometallic counterpart 29 (Figure 8) [60]. Although there was no major effect on the light-harvesting ability upon the inclusion of second metal, the effect on the emission properties was pronounced. The monometallic complex showed fluorescence/phosphorescence emission at 498/698 nm with a minor peak at $600 \mathrm{~nm}$ $\left(\tau_{0}=6 \mu \mathrm{s}, \Phi=0.09\right)$.

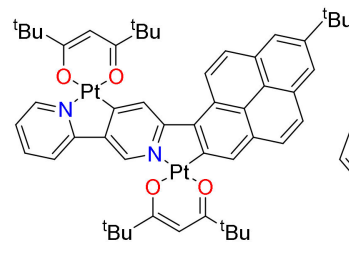

(28)

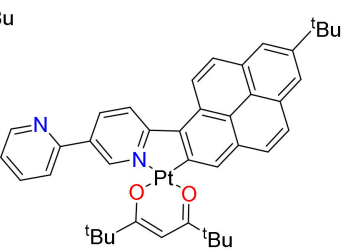

(29)

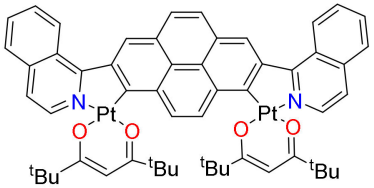

(30)

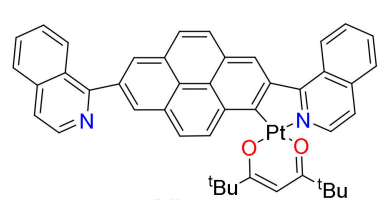

(31)

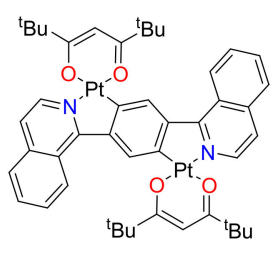

(32)

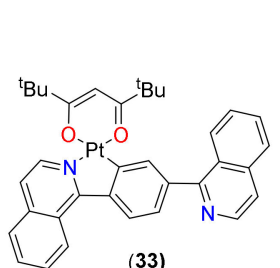

(33)

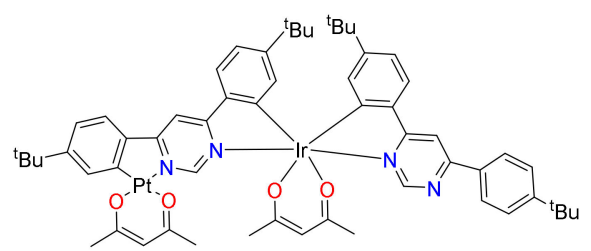

(34)

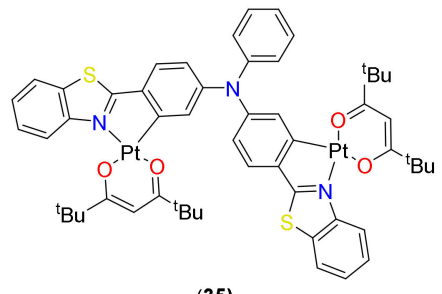

(35)

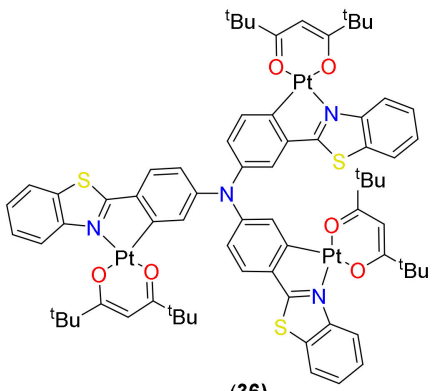

(36)

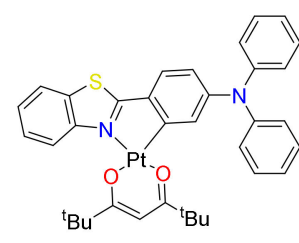

(37)

Figure 8. Mono-, di- and multinuclear Pt(II) complexes with excellent PL and OLED performances. 
Complex 28 showed slightly longer $\tau_{0}[8.36 \mu \mathrm{s}(700 \mathrm{~nm})$ and $12.81 \mu \mathrm{s}(600 \mathrm{~nm})]$ than those of the mono-nuclear complex 29 [6.53 $\mu \mathrm{s}(700 \mathrm{~nm}), 6.06 \mu \mathrm{s}(600 \mathrm{~nm})]$. In addition, a higher $\Phi$ value was reported for the bimetallic complex 28 ( 0.17 at $697 \mathrm{~nm}$ and 0.07 at $600 \mathrm{~nm}$ ] than mono-metallic 29 [0.09 at $698 \mathrm{~nm}$ ] counterparts. In the case of 28 , a similar emission profile was observed with the enhanced emission band at around $600 \mathrm{~nm}$, but reduced fluorescence emission, an indication of dual phosphorescence emission characteristics. The enhancement of the band at around $600 \mathrm{~nm}$ was attributed to the second $\mathrm{Pt}(\mathrm{II})$ center, which facilitated the formation of the ${ }^{3} \mathrm{LMCT}$ state that lies close to either the original ${ }^{3}$ MLCT state or the ${ }^{3}$ ILCT state. Other pyrene-based high-efficiency NIR-emitting mono- and bimetallated $\mathrm{Pt}(\mathrm{II})$ complexes were reported by Liu and coworkers [61]. Using a shoulder-to-shoulder type A-D-A ligand, complex 30 (Figure 8) was synthesized and compared with the monomeric counterparts 31 (Figure 8). A similar enhanced intramolecular SOC effect along with improved photophysical properties was observed. Unlike the previous example, the introduction of a second metal ion improved the light-harvesting ability and caused red shift and lowering of the band gap $\left(\mathrm{E}_{\mathrm{g}}=2.15\right.$ and $\left.1.88 \mathrm{eV}\right)$. Similarly, emission studies reveal bathochromic shift of the emission maxima to deep red region by $74 \mathrm{~nm}$, with $\Phi=16.94 \%, \tau=0.39 \mu \mathrm{s}$.

A deep red-NIR emission was also noted in complex 32 (Figure 8). Compared to the mono-metallic complex 33 (Figure 8) $(\lambda=618 \mathrm{~nm}, \Phi=2.42 \%, \tau=0.37 \mu \mathrm{s})$, the bimetallic complex 32 showed 112-nm red-shifted NIR emission $(\lambda=730 \mathrm{~nm}, \Phi=0.77 \%, \tau=0.26 \mu \mathrm{s}$, Table 2) [62]. A red phosphorescence $(\lambda=615 \mathrm{~nm}, \Phi=0.85, \tau=0.64 \mu \mathrm{s})$ was also reported for complex 34 (Figure 8) [63]. In this complex, the $\operatorname{Ir}(\mathrm{III})$ centre plays the dominant role than $\mathrm{Pt}(\mathrm{II})$ in modulating triplet level. Interestingly, this complex reveals very high radiative rate $\left(k_{\mathrm{r}}=1.33 \times 10^{6} \mathrm{~s}^{-1}\right)$, better than various $\mathrm{Pt}(\mathrm{II})$ and $\operatorname{Ir}(\mathrm{III})$ complexes. Wong and coworkers [64] demonstrated that the emission can be shifted to red and a photoluminescence quantum yield can be increased by increasing the number of metallic fragments 35-37 (Figure 8). Moreover, by incorporating more Pt(II) centers, the phosphorescence emission can be greatly enhanced, with the photoluminescence quantum yield (PLQY) increasing from 0.24 to 0.74 in solutions.

Table 2. Absorption and emission profiles of some selected mono- and bimetallic $\mathrm{Pt}(\mathrm{II})$ cyclometalated complexes.

\begin{tabular}{|c|c|c|c|c|c|}
\hline \multirow[b]{2}{*}{ S. No. } & \multicolumn{4}{|l|}{ PL Parametres } & \multirow[t]{2}{*}{ Ref. } \\
\hline & $\begin{array}{c}\lambda_{\text {abs }}{ }^{\mathrm{a}} \mathrm{nm}, \\
\left(\varepsilon \times 10^{-4} \mathbf{M}^{-1} \mathrm{~cm}^{-1}\right)\end{array}$ & $\begin{array}{l}\lambda_{\mathrm{PL}}{ }^{\mathrm{a}} \\
(\mathrm{nm})\end{array}$ & $\begin{array}{l}\Phi^{a} \\
(\%)\end{array}$ & $\begin{array}{c}\tau_{0} \\
(\mu \mathrm{s})\end{array}$ & \\
\hline 30 & $\begin{array}{c}601(0.44), 435 \text { (1.64), } 383 \text { (7.75), } 318 \text { (3.79), } \\
275(4.27)\end{array}$ & 704 & 16.94 & $0.39^{b}$ & [61] \\
\hline 31 & $504(0.48), 364$ (9.09), $329(4.73), 285$ (5.43) & 630 & 21.44 & $0.45^{\mathrm{b}}$ & [61] \\
\hline 32 & $\begin{array}{c}570(6.6), 535(6.1), 450(1.3), 424(1.2), 392 \\
(2.8), 375(2.0), 310(3.4), 286(4.0)\end{array}$ & 730 & 0.77 & $0.26^{c}$ & [62] \\
\hline 33 & $\begin{array}{c}413(0.97), 369(2.15), 352(1.81), 325(2.22) \\
270(3.06), 280(2.87)\end{array}$ & 618 & 2.42 & $0.37^{c}$ & [62] \\
\hline
\end{tabular}

${ }^{\mathrm{a}}$ in $\mathrm{CH}_{2} \mathrm{Cl}_{2}$ solution, ${ }^{\mathrm{b}}$ in degassed toluene, ${ }^{\mathrm{c}}$ in degassed $\mathrm{CH}_{2} \mathrm{Cl}_{2}$.

\section{Applications}

\subsection{Organic Photovoltaics (OPVs)}

Photovoltaic cells or photoelectric cells are electrical devices that convert light energy to electrical energy through a photovoltaic effect [65]. In the quest for renewable energy sources, researchers have been investigating the organic, inorganic and organic-inorganic hybrid compounds [66]. Owing to their cost-effectiveness, light weight, high flexibility and ease of processing, $\pi$-conjugated materials have attracted the attention of researchers to explore the possibility of application in OPV devices [67-69]. Although still lagging behind the value (efficiency) required for commercialization, recent decades saw an excellent advancement in the field of organic photovoltaics utilizing small molecules to large 
polymers $[7,70,71]$. Organic $\pi$-conjugated materials coordinated with heavy metals were also found to display enhanced generation of triplet excited states yielding moderate to high efficiency [72-74].

In general, to efficiently convert light to electricity, a material should possess balanced light absorption, mobility of charges and the diffusion length of excitons [75]. Researchers are working towards one or more of these aspects to develop materials with high efficiency. For example, it has been demonstrated that the combination of a $\pi$-conjugated D-A units result in low $\mathrm{E}_{\mathrm{g}}$ materials with absorption spanning the visible region of the solar spectrum. Similarly, tuning the planarity, introducing NCI, enhancement of intermolecular $\pi-\pi$ interactions and self-assembly etc. are some other excellent approaches to obtain highperformance materials [7].

Recently, a new structural design strategy of random terpolymers has been found to be an effective approach for designing new conjugated polymer materials. Unlike the conventional D-A alternating copolymers, terpolymers are comprised of three different monomeric units as the repeating group in the conjugated polymer backbone. Attempts have also been made to realize OPV based on the small-to-large donor sas well as acceptor active layers using cyclometalated Pt(II) complexes. Polymers containing cyclometalated $\mathrm{Pt}(\mathrm{II})$ units in the main chain and side chain have been assessed. Fréchet and coworkers [76] demonstrated that thiophene- and fluorene-containing polymers 38 (Figure 9) are excellent alternatives to platina-ynes, possibly due to the greater extent of SOC in cyclometalated complexes [15]. They reported that the thiophene-containing cyclometalated polymer exhibits much better performance $\left(J_{\mathrm{sc}}=5.3 \mathrm{~mA} / \mathrm{cm}^{2}, \mathrm{~V}_{\mathrm{oc}}=0.65 \mathrm{~V}, \mathrm{FF}=0.37, \mathrm{PCE}=1.29 \%\right)$ than fluorene containing polymer $\left(J_{\mathrm{sc}}=3.5 \mathrm{~mA} / \mathrm{cm}^{2}, \mathrm{~V}_{\mathrm{oc}}=0.38 \mathrm{~V}, \mathrm{FF}=0.30, \mathrm{PCE}=0.4 \%\right)$. This difference in the performance was attributed to the better overlap with the solar spectrum of the former. It should be noted that this value $(\mathrm{PCE}=1.29 \%)$ is much better than several poly(platina-ynes) [6,7].

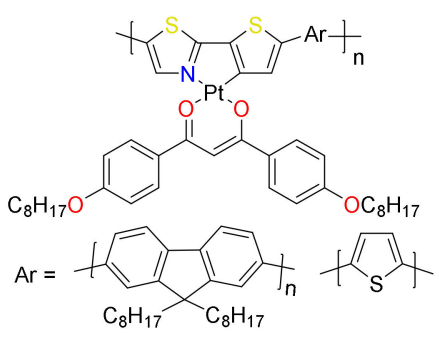

(38)

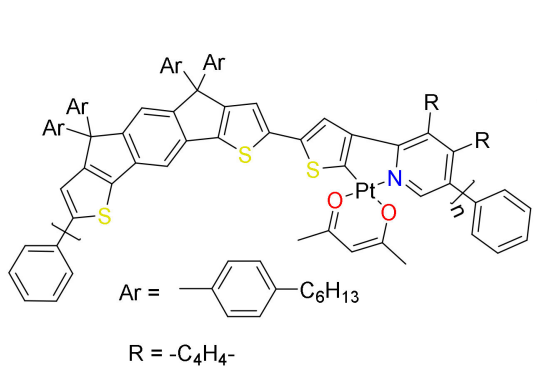

(39)

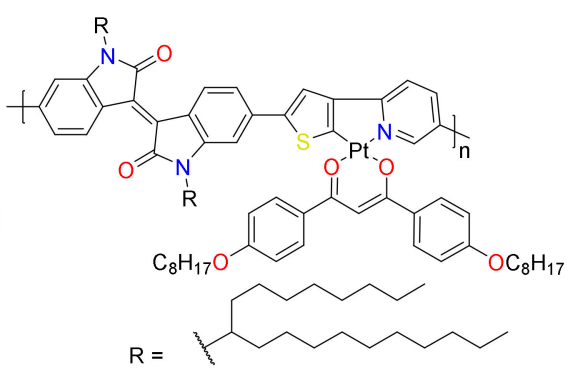

(40)

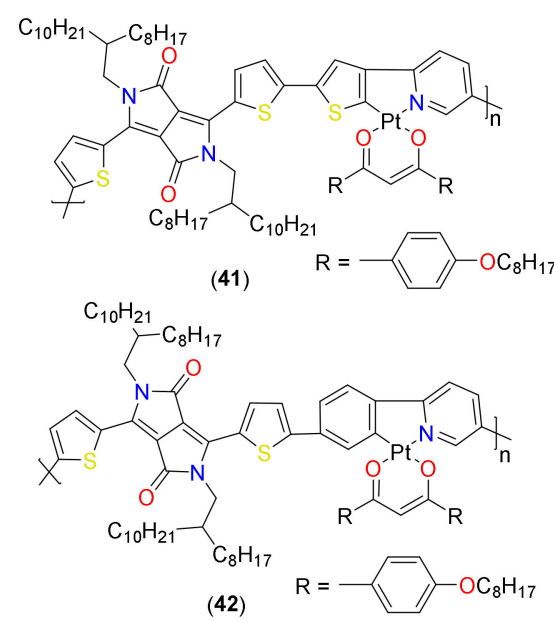

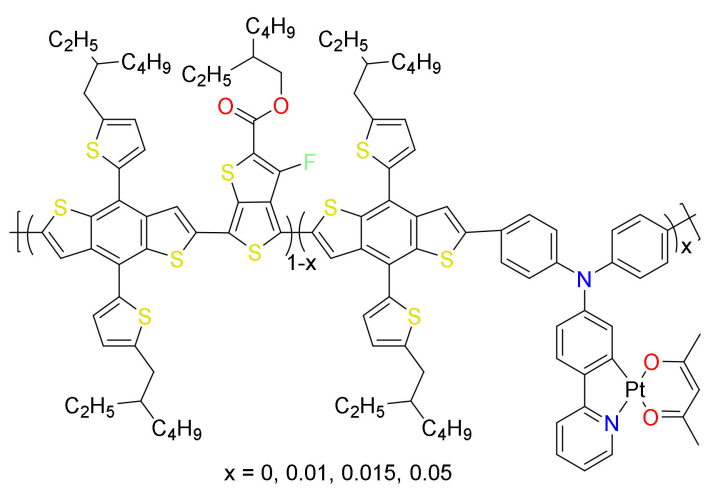

(43)

Figure 9. Cyclometalated $\mathrm{Pt}(\mathrm{II})$ complexes-based donor materials. 
Three years later, Cheng and coworkers [77] reported an indacenodithiophene-based $\pi$-conjugated polymer 39 (Figure 9 ). This new polymer showed much better performance $\left(J_{\mathrm{sc}}=4.7-7.7 \mathrm{~mA} / \mathrm{cm}^{2}, \mathrm{~V}_{\mathrm{oc}}=0.78-0.79 \mathrm{~V}, \mathrm{FF}=0.36-0.49, \mathrm{PCE}=1.7-2.9 \%\right)$ than the earlier reported polymer. The performance, which was the highest at that time, was realized using phenyl- $\mathrm{C}_{71}$-butyric acid methyl ester $\left(\mathrm{PC}_{71} \mathrm{BM}\right)$ acceptor (in contrast to the phenyl- $\mathrm{C}_{61^{-}}$ butyric acid methyl ester (PCBM) used in an earlier study). The incorporation of $\mathrm{Pt}(\mathrm{II})$ fragment red-shifted the absorption band, lowered the frontier orbital energy levels and improved the solar cell performance compared to metal-free polymers $\left(J_{\mathrm{sc}}=3.5-4.0 \mathrm{~mA} / \mathrm{cm}^{2}\right.$, $\mathrm{V}_{\mathrm{OC}}=0.69-0.80 \mathrm{~V}, \mathrm{FF}=0.32-0.44, \mathrm{PCE}=0.9-1.2 \%$ ). A further change in the cyclometalated $\mathrm{Pt}(\mathrm{II})$ "auxochrome units" and $\pi$-conjugated organic spacer led to a donor material 40 (Figure 9) of which the performance depends on the amount of acceptor selected (greater the amount of PCBM, better the performance) [78].

Under optimized conditions, an active layer composed of donor $\mathbf{4 0}$ exhibits relatively low performance $(\mathrm{PCE}=0.22 \%$ ), which was attributed to various factors (poor phase separation, low energy level of triplet state in the polymer, and weakly exothermic charge transfer from the singlet to PCBM). Later, the same group carried out comparative photophysical, PV and organic field-effect transistor (OFET) studies using two organometallic polymers 41 and 42 (Figure 9) [79]. These two polymers exhibited excellent absorption profiles and respectable PV performance. For instance, thiophene-containing polymer 41 showed $J_{\mathrm{sc}}=3.79 \mathrm{~mA} / \mathrm{cm}^{2}, \mathrm{~V}_{\mathrm{oc}}=0.65 \mathrm{~V}, \mathrm{FF}=63.86, \mathrm{PCE}=1.66 \%$ while phenylene containing polymer 42 exhibited $J_{\mathrm{sc}}=1.61 \mathrm{~mA} / \mathrm{cm}^{2}, \mathrm{~V}_{\mathrm{oc}}=0.73 \mathrm{~V}, \mathrm{FF}=41.37, \mathrm{PCE}=0.52 \%$. Notably, polymer 41 showed a better performance and a high FF ( $65 \%)$ with higher loading of the acceptor $\mathrm{PC}_{71} \mathrm{BM}$. The low PCE for $35(\sim 0.52 \%)$ can be attributed to its blue-shifted absorption compared to $\mathbf{4 1}$, as well as poor nanoscale phase separation observed with $\mathrm{PC}_{71} \mathrm{BM}$ in the active layer.

In a recent work, Huang and coworkers [80] compared the properties and performances of organic and organometallic random terpolymers 43 (Figure 9). Despite the fact that these two classes of materials exhibit almost similar optical properties $\left(E_{g}^{o p}=1.56 \mathrm{eV}\right.$ for organic vs. 1.53-1.56 eV for organometallic polymers), there was a marked difference in their OPV performance. For instance, the device based on donor polymer grafted with $1.5 \mathrm{~mol} \%$ cyclometalated Pt(II) complex showed a maximum PCE of $8.45 \%$ $\left(J_{\mathrm{sc}}=16.21 \mathrm{~mA} / \mathrm{cm}^{2}, \mathrm{~V}_{\mathrm{oc}}=0.80 \mathrm{~V} \mathrm{~V}, \mathrm{FF}=65.01 \%\right)$ while its organic counterpart exhibited a PCE of $7.92 \%\left(J_{\mathrm{sc}}=14.98 \mathrm{~mA} / \mathrm{cm}^{2}, \mathrm{~V}_{\mathrm{oc}}=0.81 \mathrm{~V} \mathrm{~V}, \mathrm{FF}=65.10 \%\right)$. This difference in performance was attributed to the higher hole mobility, limited bimolecular recombination and charge separation in the organometallic polymer. However, increasing the $\mathrm{Pt}(\mathrm{II})$ content $(5 \mathrm{~mol} \%)$ in the polymer did not enhance the performance $\left(J_{\mathrm{sc}}=13.50 \mathrm{~mA} / \mathrm{cm}^{2}\right.$, $\mathrm{V}_{\mathrm{OC}}=0.81 \mathrm{~V}, \mathrm{FF}=66.21, \mathrm{PCE}=7.24 \%$ ) due to its reduced charge transport.

In addition to the above-discussed donor layers in bulk heterojunction (BHJs), cyclometalated complexes have also been utilized for the fabrication of all of the polymer solar cells (all-PSCs) in which both the p-type (donor) and the n-type (acceptor) active layers are composed of the conjugated polymer. Compared to the other architectures, all PSCs are considered more suitable for large-scale applications due to their long-term optical, mechanical, thermal and morphological stabilities and fullerene-free nature. However, the development of high-performance all-PSCs is challenging due to the limited number of ntype polymers and relatively difficult control of polymer aggregation behavior [81]. It was found that the chemical conjugation of a certain amount of cyclometalated $\mathrm{Pt}(\mathrm{II})$ complex for random terpolymer acceptors facilitates exciton dissociation, while the introduction of the corresponding pure, organic main ligand exhibited the opposite phenomenon [81]. Cyclometalated $\mathrm{Pt}(\mathrm{II})$ complex containing polymers have been utilized to form an active layer (both as donor and acceptor) in all PSCs. For instance, a very first example of allPSC constructed using random terpolymer acceptors 44 (Figure 10) was reported by Tao and coworkers [82]. They judiciously introduced various feed ratio (1, 2, and $5 \mathrm{~mol} \%) \mathrm{Pt}$ complex as the third monomer into the conjugated backbone of a well-known acceptor 
polymer poly[[N,N'-bis(2-octyl dodecyl)-naphthalene-1,4,5,8-bis(dicarboximide)-2,6-diyl]alt-5,5'-(2,2'-bithiophene)] (PNDIT2) to realize organometallic acceptor polymer.

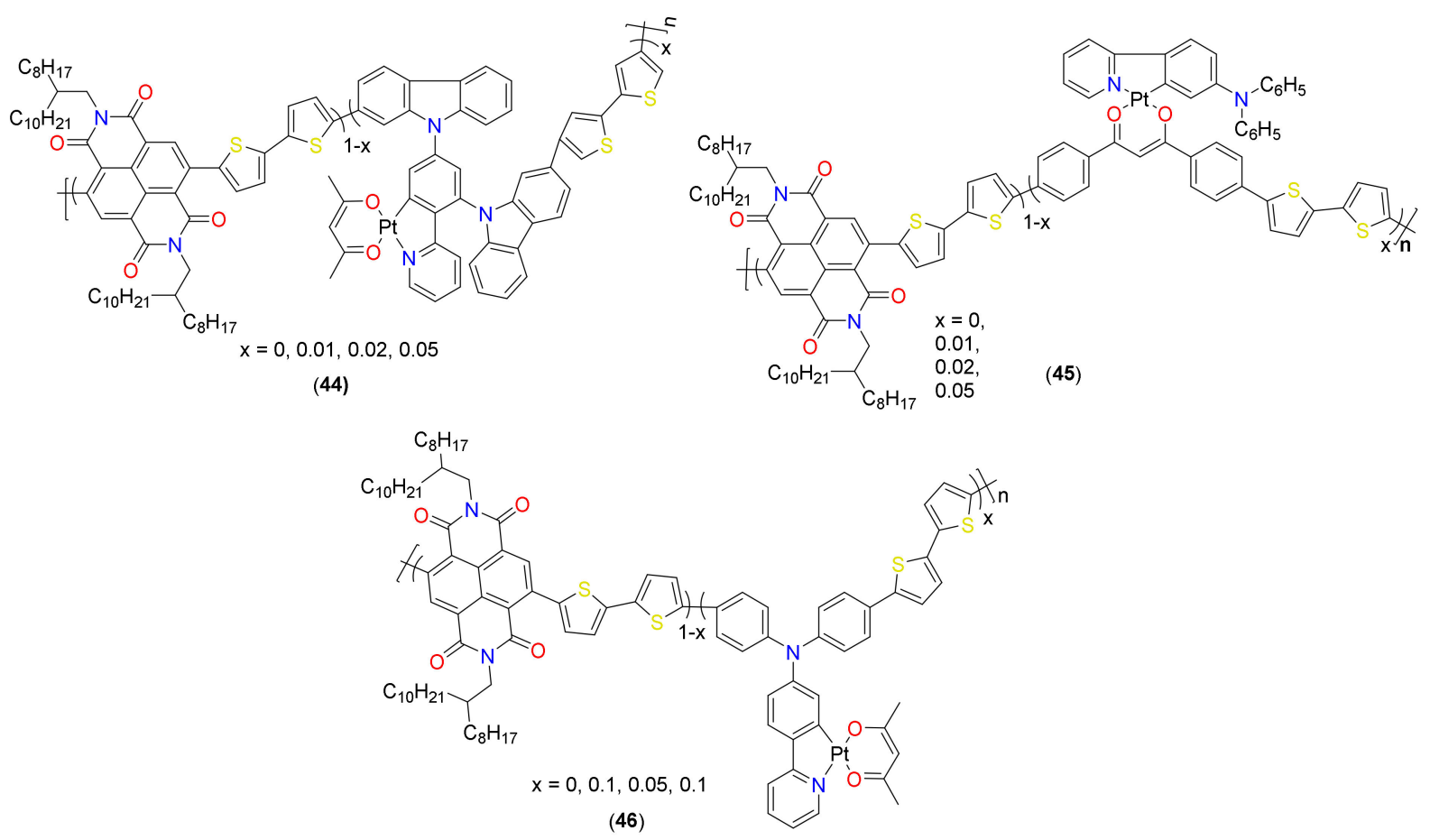

Figure 10. Cyclometalated Pt(II) complexes-based acceptor polymers for all-PSCs.

Compared to their organic counterparts, organometallic polymers exhibited better features (viz. melting point, crystallization temperature, FMO energy levels) and PV performance $\left(J_{\mathrm{sc}}=11.73 \mathrm{~mA} / \mathrm{cm}^{2}, \mathrm{~V}_{\mathrm{oc}}=0.79 \mathrm{~V}, \mathrm{FF}=0.49, \mathrm{PCE}=4.51 \% \mathrm{vs} . J_{\mathrm{sc}}=10.44 \mathrm{~mA} / \mathrm{cm}^{2}\right.$, $\left.\mathrm{V}_{\mathrm{oc}}=0.79 \mathrm{~V}, \mathrm{FF}=0.48, \mathrm{PCE}=3.88 \%\right)$ with the donor poly $([2,6$ '-4,8-di(5-ethylhexylthienyl) benzo[1,2-b;3,3-b]dithiophene]\{3-fluoro-2[(2-ethylhexyl)carbonyl]thieno[3,4-b] thiophenediyl\}) (PTB7-Th). In this case, it was realized that the polymer with low $\mathrm{Pt}(\mathrm{II})$ content is best suited to fabricate both conventional and inverted BHJs as they possess higher exciton transport ability, well-interpenetrated nanoscale phase-separated network and efficient charge separation. However, the polymer with higher $\mathrm{Pt}(\mathrm{II})$ content $(5 \%)$ showed lower performance $\left(J_{\mathrm{sc}}=11.09 \mathrm{~mA} / \mathrm{cm}^{2}, \mathrm{~V}_{\mathrm{oc}}=0.79 \mathrm{~V}, \mathrm{FF}=0.47, \mathrm{PCE}=4.14 \%\right)$ due to poor charge transport and low optical absorption behavior. The same group [83] reported $\mathrm{Pt}(\mathrm{II})$ complex-based terpolymer acceptors 45 (Figure 10) using another well-known acceptor PNDIT2. The new acceptor polymers were realized by replacing the naphthalene diimide unit with varying amount of $\mathrm{Pt}(\mathrm{II})$ complex, $(\mathrm{dbm}) \mathrm{PtPyTPA}(\mathrm{dbm}=$ dibenzoylmethane, TPA = triphenylamine).

Like others, the new $\mathrm{Pt}(\mathrm{II})$ acceptors showed properties comparable to organic counterpart $\left(E_{g}^{o p}=1.45 \mathrm{eV}\right.$ for organic vs. $1.47-1.48 \mathrm{eV}$ for organometallic polymers). Similar to the previous example, both the conventional and inverted configurations of all-PSCs showed better performance (Figure 11, values taken from Refs. [82,83]). For example, under optimized condition, a conventional BHJ device composed of $5 \%$ acceptor showed the maximum PCE of $3.97 \%\left(J_{\mathrm{sc}}=9.09 \mathrm{~mA} / \mathrm{cm}^{2}, \mathrm{~V}_{\mathrm{oc}}=0.77 \mathrm{~V}, \mathrm{FF}=0.37\right)$, which was almost double than the metal-free counterpart $\left(J_{\mathrm{sc}}=11.09 \mathrm{~mA} / \mathrm{cm}^{2}, \mathrm{~V}_{\mathrm{oc}}=0.79 \mathrm{~V}, \mathrm{FF}=0.47\right.$, $\mathrm{PCE}=2.58 \%$ ). They also found that when the donor polymer PNDIT2 in a conventional device is replaced by another Pt-containing terpolymer donor, the PCE value drastically enhanced $(\mathrm{PCE}=3.97 \% \rightarrow 6.18 \%$ ) A similar trend was reported for inverted $\mathrm{BHJs}$, albeit with relatively low enhancement (34\% higher). The higher performance was attributed to more efficient exciton separation, less charge recombination and higher hole and electron mobilities with enhanced $J_{\mathrm{sc}}$ and FF. Overall, these works have firmly established the 
importance of incorporating cyclometalating Pt(II) fragments to realize high-performance donor and acceptor materials.

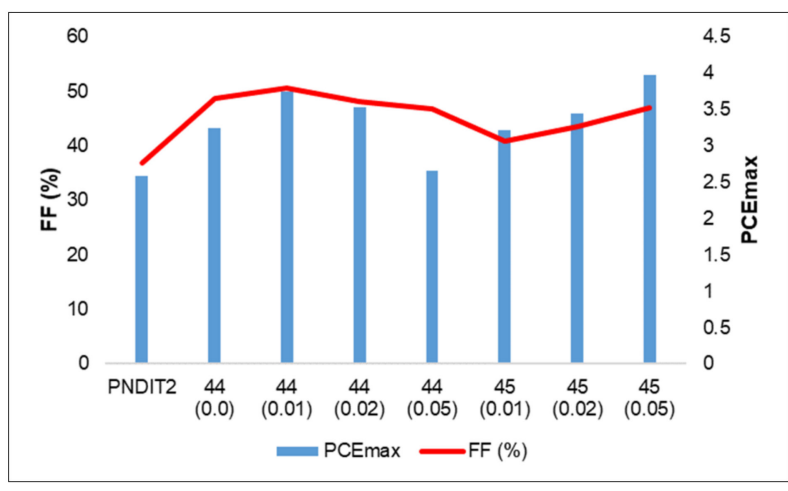

(a)

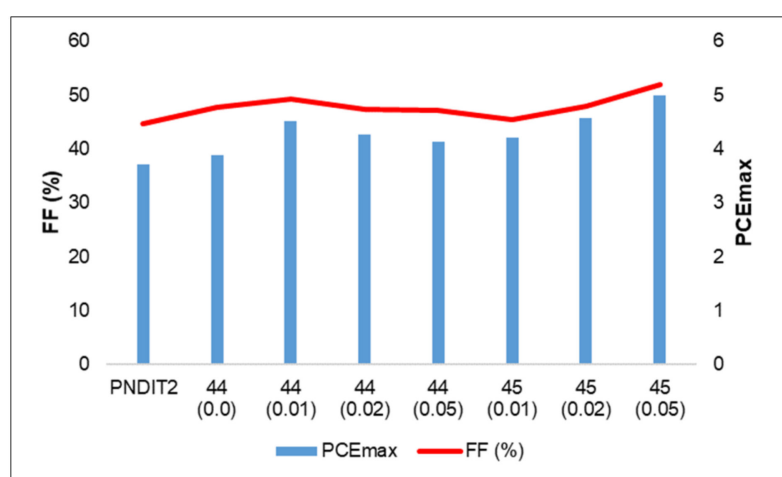

(b)

Figure 11. Variation of FF and PCE in (a) conventional (ITO/PEDOT:PSS/PTB7-Th:44-45/PDIN/Al) and (b) inverted (PTB7-Th:44-45) cells with Pt(II) content. Value given in the parenthesis indicates certain amount (\%) of Pt(II) cyclometalated complex.

To underpin the underlying mechanism of an enhanced PV performance, Tao and coworkers [81] assessed the PV performance of terpolymer acceptors 46 (Figure 10) prepared by embedding PyTPAPt(acac) (PyTPA = N,N'-Bis(4-bromophenyl)-4-(4-pyridinyl)benzenamine) as the third monomer into the PNDIT2. They noted that as the feed ratio of PyTPAPt(acac) complex increases from 1 to 5 and 10\%, its PCE value also increased (2.49 to 2.85 and $3.16 \%$, respectively). On the other hand, low PCE $(1.85-2.47 \%)$ was found for metal-free terpolymers. They attributed these opposite PCE trends to the differences in film morphology (instead of triplet excitons in organometallic polymers) and enhanced carrier mobility, suppressed bimolecular recombination as well as improved exciton dissociation rate and charge transferability. They found that the poor molecular packing is beneficial in polymer blends while highly crystalline structure is detrimental for obtaining highperforming terpolymer acceptors suitable for all PSCs.

\subsection{Organic Light-Emitting Diodes (OLEDs)}

As discussed in the previous section, phosphorescent cyclometalated Pt(II) complex bearing materials are promising candidates for the development of OPVs. These materials have also shown potential for organic light-emitting diodes (OLEDs) due to their high PLQY, short nonradiative lifetime, and high thermal stability [5]. In addition, the square planar geometry assists in making a strong intermolecular interaction (viz. $\pi$ and $\pi^{*}$ orbitals of conjugated organic ligand and $\mathrm{Pt} . . . \mathrm{Pt}$ ) between the discrete units, leading to bathochromic excimer emission. The co-existence of both the monomer and the excimer can produce a broad emission band that covers the entire visible region, resulting in white light emission that makes it possible to apply in organic lighting. High color purity and defined emission wavelengths are the added benefits offered by such materials. Using such materials, blue and white emitters can be realized, which are otherwise difficult. Complexes $21\left(R_{1}=R_{2}=\right.$ Me; $R_{3}$ and $R_{5}=H ; R_{4}$ and $R_{6}=F$, Figure 5) and 47-50 (Figure 12) are some of the representative examples of emitters based on cyclometalated $\mathrm{Pt}(\mathrm{II}) \beta$-diketonate complexes reported for the fabrication of blue, red and white OLEDs with external quantum efficiency (EQE) 8.5-16\% [84]. In addition, multimetallic complexes 28-37 (Figure 8) are also some of the recent examples with outstanding OLED performances. For example, OLED device based on bimetallic complex 28 (Figure 8) showed better external quantum efficiency ( $\mathrm{EQE}=0.31 \%$ at $16 \mathrm{wt} \%$ ) and other parameters as compared to its monometallic counterpart (EQE $=0.14 \%$ at $16 \mathrm{wt} \%$ ). OLED fabricated using complex 30 (Figure 8 ) exhibited a NIR emission peak at $700 \mathrm{~nm}$ with EQE of $6.06 \%$. Similarly, binuclear 35 (Figure 8) and trinuclear 36 (Figure 8) emitters [64] outperformed their monometallic counterparts. 
Whereas complex 35 showed $\mathrm{EQE}=10.5 \%$, current efficiency $(\mathrm{CE})=21.4 \mathrm{~cd} / \mathrm{A}$, and power efficiency $(\mathrm{PE})=12.9 \mathrm{~lm} / \mathrm{W}$, complex 36 showed $\mathrm{EQE}=17.0 \%, \mathrm{CE}=35.4 \mathrm{~cd} / \mathrm{A}$, and $\mathrm{PE}=27.2 \mathrm{~lm} / \mathrm{W}$. Recently, a trinuclear complex has been reported to have $\mathrm{EQE}=16.92 \%$, $\mathrm{CE}=56.74 \mathrm{~cd} / \mathrm{A}$, and $\mathrm{PE}=29.09 \mathrm{~lm} / \mathrm{W}$ [85]. Indeed, these values are among the highest reported for the multinuclear Pt(II) complex-based OLEDs.

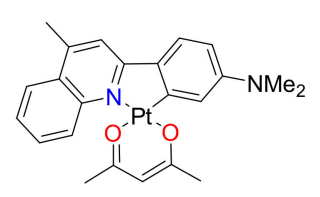

(47)

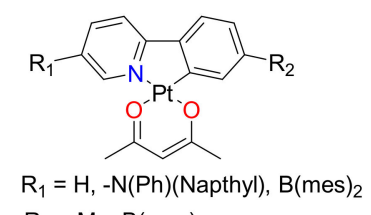

$\mathrm{R}_{2}=\mathrm{Me}, \mathrm{B}(\mathrm{mes})_{2}$

(48)

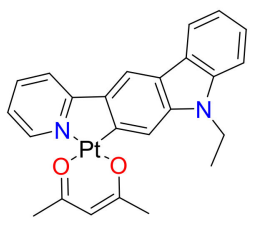

(49)

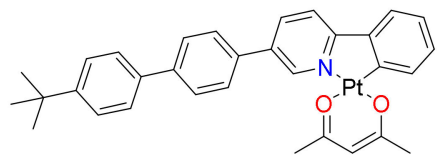

(50)

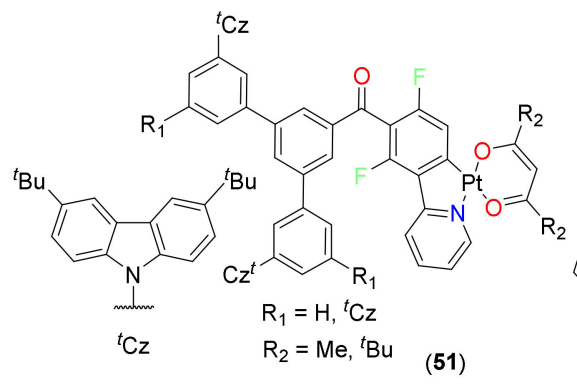

(51)

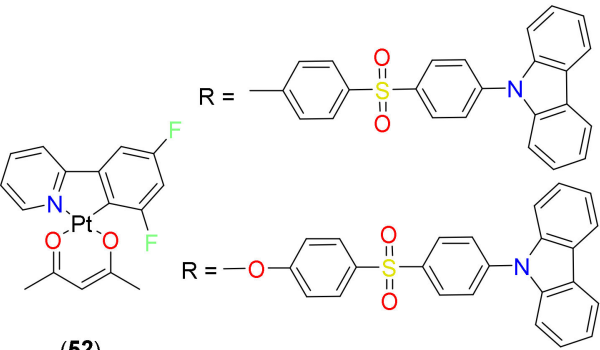

(52)

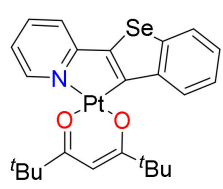

(53)

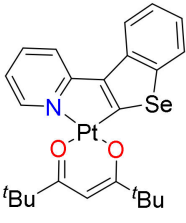

(54)

Figure 12. Cyclometalated $\mathrm{Pt}(\mathrm{II})$ complexes-based luminophores for OLEDs.

In order to delineate the structural and electronic influences on the emission properties, Strassner and coworkers [18] reported thiazol-2-ylidene $\mathrm{Pt}(\mathrm{II})$ complexes based on the Nphenyl-4,5-dimethyl-1,3-thiazol-2-ylidene NHC ligand and seven different $\beta$-diketonate ligands. They found that complex $\mathbf{1 7}\left(\mathrm{R}_{1}=\mathrm{R}_{2}=\mathrm{Me} ; \mathrm{R}_{4}=\mathrm{R}_{5}=\mathrm{R}_{6}=\mathrm{H} ; \mathrm{R}_{3}=\right.$ mes Figure 4$)$ exhibits promising thermal stability, high quantum yields with a decay lifetime of $10.0 \mu \mathrm{s}$ and stable emission properties in neat films. Interestingly, the emission spectra of the complex were independent of the type $\beta$-diketonate ligand selected, which is quite sensitive in other $\left(\mathrm{C}^{\wedge} \mathrm{C}\right) \mathrm{Pt}\left(\mathrm{O}^{\wedge} \mathrm{O}\right)$ derivatives such as imidazole or triazole NHCs containing complexes. Under optimized condition, a mixed-matrix OLED device doped with $15 \%$ of complex 17 $\left(\mathrm{R}_{1}=\mathrm{R}_{2}=\mathrm{Me} ; \mathrm{R}_{4}=\mathrm{R}_{5}=\mathrm{R}_{6}=\mathrm{H} ; \mathrm{R}_{3}=\right.$ mes, Figure 4$)$ showed EQE $=12.3 \%, \mathrm{LE}=24.0 \mathrm{~lm} / \mathrm{W}$ and $\mathrm{CE}=37.8 \mathrm{~cd} / \mathrm{A}$ at $300 \mathrm{~cd} / \mathrm{m}^{2}$ with a green emission color. This performance was better than the previously reported $\mathrm{C}^{\wedge} \mathrm{C}^{*}$ cyclometalated $\mathrm{Pt}(\mathrm{II})$ complexes $[29,86]$. For instance, $\mathrm{C}^{\wedge} \mathrm{C}^{*}$ cyclometalated $\mathrm{Pt}(\mathrm{II})$ complexes $2(\mathrm{R}=$ duryl, Figure 2$)$ based on imidazole NHC ligands and acac derivatives exhibited EQE $12.6 \%, \mathrm{LE}=11.9 \mathrm{~lm} / \mathrm{W}$ and $\mathrm{CE}=25.2 \mathrm{~cd} / \mathrm{A}$ with a blue emission [29]. In such complexes, auxiliary ligands with bulky groups protect the central metal and prevent the square-planar complexes from aggregation. Methyl substituted diaryl diketonate ligands were found to be the best choice as co-ligands in combination with 1,3-diphenylbenzo[d]imidazol-2-ylidene (dpbic) as NHC ligand because they facilitate good solubility, steric protection and desirable photophysics. It was found that the presence of an additional iridium hole-transporter in the emissive layer improved the device lifetime by a factor of seven.

Recently, Kang and coworkers [54] carried out an extensive study to delineate the relationship between intermolecular interactions in the solid state and OLED performance (23, Figure 5). They successfully demonstrated that the incorporation of a bulky TMS group at two different positions on the $2^{\prime}, 6^{\prime}$-difluoro-2,3'-bipyridine chelate ligand is an effective strategy to enhance the PLQY. The WOLED doped with $23(\mathrm{R}=5$-TMS) exhibits the highest $\mathrm{EQE}=12.3 \%$, while the WOLEDs doped with $23(\mathrm{R}=$ none) and $23(\mathrm{R}=4$-TMS) exhibit similar EQEs $=7.2 \%$ and $7.6 \%$, respectively. The low EQE of the device doped with $23(R=$ none $)$ is due to its low PLQY. The current efficiency and power efficiency are 
also high in the WOLEDs doped with the $\mathbf{2 3}(\mathrm{R}=5$-TMS). In the EL spectra, all devices emit in both the blue and red wavelength regions; blue emission is caused by the intrinsic emission of the blue phosphor monomer, and the red emission is due to excimer emission. A bathochromic shift of the peak wavelength both in the blue and red emission regions were observed in the devices containing $23(\mathrm{R}=4$-TMS) and 23 ( $\mathrm{R}=5$-TMS).

WOLEDs by utilizing excimer-based electroluminescence (EL) were also reported by using Pt(II) complexes 51 (Figure 12) bearing peripheral carbazole moieties [87]. The complexes exhibited monomer and excimer emissions in the film state, and their ratios were varied by the steric hindrance of the cyclometalated and ancillary ligands. The devices using the acac complexes exhibited predominantly excimeric EL, whereas the dipivaloylmethanate $\left(\mathrm{R}={ }^{\mathrm{t}} \mathrm{Bu}\right)$ complexes exhibited white EL accompanied by a high average color rendering index (CRI) of 81 due to the balanced blue monomer and orange excimer emissions Using complex $22\left(\mathrm{R}_{1}=\mathrm{R}_{2}=\mathrm{F}\right)$ as a single emitting dopant, a pseudowhite OLED with CIE chromaticity coordinates of $(0.42,0.42)$ was also fabricated that showed maximum current efficiency of $16.0 \mathrm{~cd} / \mathrm{A}$ [53].

Wei et al. [88] proposed that the molecule should not only possess planar structure but also have appropriate steric hindrance, in which the planar moiety can possess good intermolecular $\pi-\pi$ interaction and the steric hindrance affects the molecular packing, probably in favor of the external stimuli, such as pressure and grinding. On the other hand, the steric structure has a positive effect on suppressing the emission quenching in the solid state and increasing the solubility. The resulting hybrid molecules bearing square planar and bent shape units together exhibit stimuli-responsive emissions, enhanced solubility and application as OLED dopant (Figure 13). Bearing this in mind, they reported stimuliresponsive complexes 52 (Figure 12) having square planar and bent shape units separated by an oxygen atom. Results of solution-processable OLEDs indicated that $\mathbf{5 2}$ (O-separated) exhibits better performances with the high $\mathrm{EQE}=17.79 \%$ and $\mathrm{CE}=58.31 \mathrm{~cd} / \mathrm{A}$ than the one without oxygen $(\mathrm{EQE}=13.47 \%, \mathrm{CE}=38.45 \mathrm{~cd} / \mathrm{A})$. This high $\mathrm{EQE}$ value $(\sim 18 \%)$ is among the highest efficiency for the devices based on external-stimuli-responsive materials.

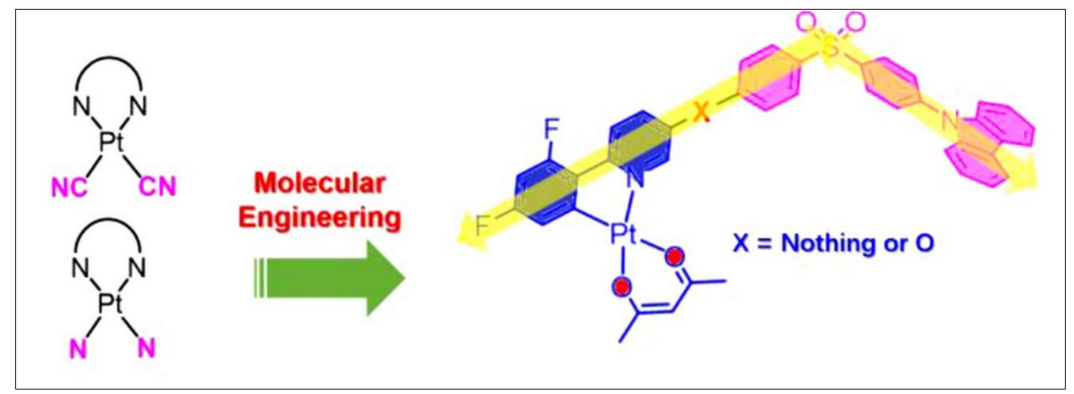

Figure 13. Molecular engineering scheme for the realization of external-stimuli-responsive OLED phosphors. Reproduced with permission from ref. [88].

Very recently, the first examples of phosphorescent $\mathrm{Pt}(\mathrm{II})$ complexes bearing 2- and 3-(2-pyridyl)benzo[b]selenophenes 53 and 54 (Figure 12) have been reported [89]. Though they possess very small differences in the molecular design, these two complexes efficiently emitted green and red phosphorescence with absolute $\Phi=0.52$ (for green) and 0.11 (for red). When used as phosphorescent dopants for hybrid solution-processable OLED, relatively low turn-on voltages $(4.2 \mathrm{~V}$ ) and maximum EQE of $0.8 \%$ (for red device) was noted. Further optimizations of dopant concentrations and/or usage of more appropriate hosts and/or additional layers are required for getting both white EL and high OLED efficiencies based on the designed complexes.

\subsection{Oxygen Sensing}

Molecular oxygen $\left(\mathrm{O}_{2}\right)$ is the most vital gas present in the atmosphere and being used by kingdom animalia and plantae for their sustenance and growth. Due to its par importance, $\mathrm{O}_{2}$ monitoring using optical sensors is an emerging area of research with wide 
applicability in the area of environmental monitoring, oceanography, and biology, as well as industries [90]. Usually, a luminescent oxygen-sensitive probe (OSP)/oxygen sensitizer displays a change in emission properties when it comes in contact with the gas. A number of OSPs based on transition metal complexes have been reported in the past [91]. The fact that the triplet ground state molecular oxygen $\left({ }^{3} \mathrm{O}_{2}\right)$ is an excellent quencher to the triplet excited-state of the metal complexes, it readily quenches the phosphorescence of the complex. Usually, cyclometalated Pt(II)/ Ir(III) complexes with $\mathrm{C}^{\wedge} \mathrm{N}$ ligands show high $\Phi$, good photostability and long $\tau$ (in $\mu$ s). The sensitivity of transition metal complexes to external stimuli and gases was exploited to create functional materials and sensors.

The development of OSPs for continuous online monitoring of molecular oxygen based on cyclometalated Pt(II) complex is well-documented [91,92]. For instance, Liu and coworkers [93] reported the very first example of a nitrile compound $55(\mathrm{R}=5-\mathrm{CN}$, Figure 14) based on cyclometalating ligand for efficient $\mathrm{O}_{2}$ sensing. In the past, the same group [92] carried out a systematic study to understand the role of substituents on C- and Ndonor fragments. They prepared a series of 2-phenylquinoline-based cyclometalated Pt(II) complexes (56, Figure 14) and demonstrated that the introduction of a diphenylamino group at the 4-position of the phenyl ring affects the HOMO level of the complex significantly, resulting in a marked decrease in Eg. On the other hand, the emission or energy gap is not influenced clearly by other substituents (methyl, cyano, fluoro, trifluoromethyl, methoxyl, carbazol-9-yl) at the 4-position of the phenyl ring. All the complexes show redshifted room-temperature phosphorescence emission (at 578-599 nm) relative to the model complex Pt(ppy)acac (at $486 \mathrm{~nm}$ ). Film containing a complex with a triphenylamino moiety, i.e., 56 exhibits the highest sensitivity $\left(K_{\mathrm{sV}}^{\mathrm{app}}=0.020 \mathrm{Torr}^{-1}\right)$. In complex $21\left(\mathrm{R}_{1}=\mathrm{R}_{2}=\mathrm{Me}\right.$; $\mathrm{R}_{3}=\mathrm{R}_{4}=\mathrm{H} ; \mathrm{R}_{5}, \mathrm{R}_{6}=4-\mathrm{C}_{6} \mathrm{H}_{4} \mathrm{~F}, 3,4-\mathrm{C}_{6} \mathrm{H}_{3} \mathrm{~F}_{2}, 3,4,5-\mathrm{C}_{6} \mathrm{H}_{2} \mathrm{~F}_{3}$, Figure 5), it was noted that the presence of a bulky fluorophenyl substituents at the para position is beneficial to oxygen sensing [51]. Higher oxygen sensitivity was attributed to the reduced intermolecular interaction and self-quenching. In general, the following trend was observed: complexes having one fluoro-substituent was more sensitive than those having two and three fluorines. Similarly, fluorophenyl group at para position on the phenyl ring of 2-ppy demonstrated higher oxygen sensitivities than the meta-analogue. Pt(II) complex substituted at the para position on the phenyl ring of ppy ligand by 3,4,5-fluorophenyl showed higher luminescent oxygen sensitivities compared to its meta-substituted counterpart [51,52].

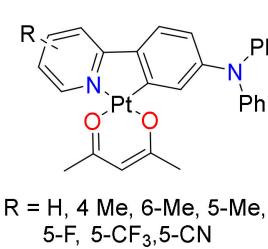

(55)

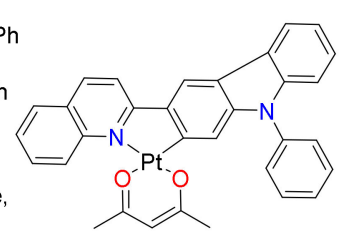

(56)

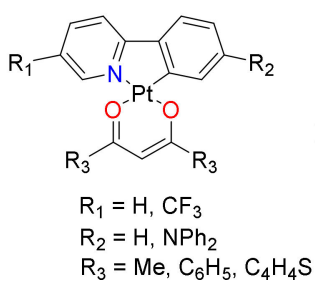

(57)

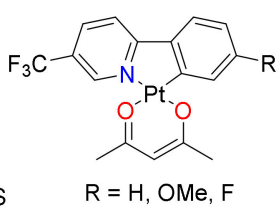

(58)

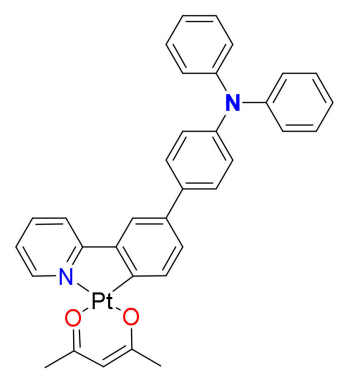

(59)

Figure 14. Cyclometalated $\mathrm{Pt}(\mathrm{II})$ complex-based oxygen sensors.

Very recently, Yu and coworkers [19] studied the effects of phenyl/thienyl substituents at acac auxiliary ligands on the properties of cyclometalated $\mathrm{Pt}(\mathrm{II})$ complexes 57 (Figure 14). Films prepared by immobilizing complexes in the ethyl cellulose (EC) was used as OSPs and revealed that $57\left(R_{1}=C F_{3}, R_{2}=N_{2}\right.$ and $\left.R_{3}=P h\right)$ demonstrates the highest sensitivity (Figure 15A). Moreover, the phosphorescence quenching and recovery processes of the oxygen sensing films are reversible (4000 s) and provide excellent operational stability. These results show that the phosphorescence lifetimes and oxygen sensitivity of the cyclometalated $\mathrm{Pt}(\mathrm{II})$ complexes could be tuned by the structures of $\beta$-diketone ancillary ligands. 


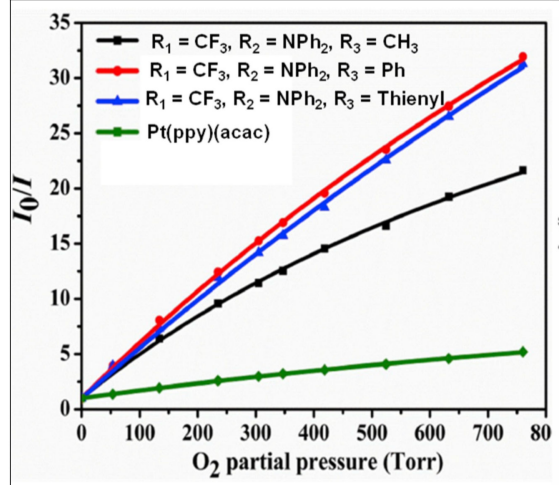

(A)

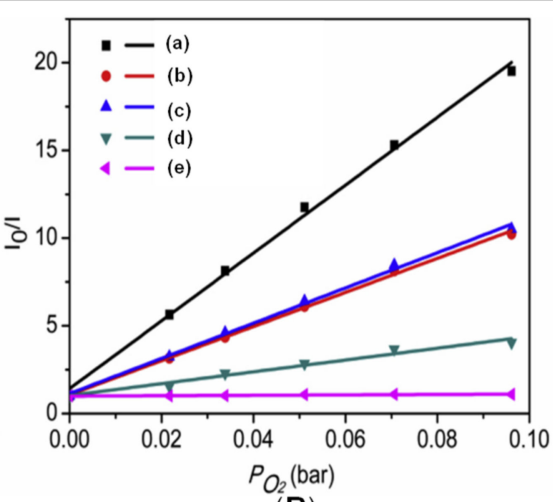

(B)

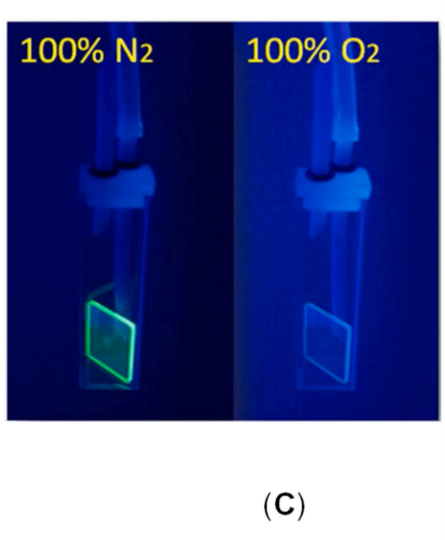

Figure 15. Stern Volmer plots of (A) complex 57 immobilized on EC films, (B) complex 21 in THF (a: $R_{1}=R_{2}=$ Me; $\mathrm{R}_{3}=\mathrm{R}_{4}=\mathrm{R}_{5}=\mathrm{H} ; \mathrm{R}_{6}=\mathrm{C}_{6} \mathrm{H}_{5}, \mathrm{~b}: \mathrm{R}_{1}=\mathrm{R}_{2}=\mathrm{Me} ; \mathrm{R}_{3}=\mathrm{R}_{4}=\mathrm{R}_{5}=\mathrm{H} ; \mathrm{R}_{6}=2,4-\mathrm{C}_{6} \mathrm{H}_{3} \mathrm{~F}_{2}, \mathrm{c}: \mathrm{R}_{1}=\mathrm{R}_{2}=\mathrm{Me} ; \mathrm{R}_{3}=\mathrm{R}_{4}=\mathrm{R}_{5}=\mathrm{R}_{6}=\mathrm{H}, \mathrm{d}$ : $\mathrm{R}_{1}=\mathrm{R}_{2}=\mathrm{Me} ; \mathrm{R}_{3}=\mathrm{R}_{4}=\mathrm{R}_{5}=\mathrm{H} ; \mathrm{R}_{6}=\mathrm{F}$, e: $\mathrm{R}_{1}=\mathrm{R}_{2}=\mathrm{Me} ; \mathrm{R}_{3}=\mathrm{R}_{5}=\mathrm{H} ; \mathrm{R}_{4}=\mathrm{R}_{6}=\mathrm{F}$ ) and (C) The luminescence photographs of 59 film under $100 \% \mathrm{~N}_{2}$ and $100 \% \mathrm{O}_{2}$ (excited at $365 \mathrm{~nm}$ ). Reproduced with permission from ref. [19,52,94].

In another study, the same group [52] assessed the effects of fluorine and phenyl substituents on oxygen sensitivity and photostability of cyclometalated $\mathrm{Pt}(\mathrm{II})$ complexes $\left(21, \mathrm{R}_{1}=\mathrm{R}_{2}=\mathrm{Me} ; \mathrm{R}_{3}=\mathrm{R}_{5}=\mathrm{H} ; \mathrm{R}_{4}=\mathrm{H}, \mathrm{F} ; \mathrm{R}_{6}=\mathrm{F}, \mathrm{C}_{6} \mathrm{H}_{5}, 2,4-\mathrm{C}_{6} \mathrm{H}_{3} \mathrm{~F}_{2}\right.$, Figure 5). The phosphorescence of all $\mathrm{Pt}(\mathrm{II})$ complexes in tetrahydrofuran (THF) or immobilized in EC films were gradually quenched with increased oxygen concentration (Figure 15B). It was noted that the introduction of a phenyl group or a 2,4-difluorophenyl substituent at the para-position on the benzene ring of 2-ppy can increase oxygen sensitivity. Complex 21 $\left(\mathrm{R}_{1}=\mathrm{R}_{2}=\mathrm{Me} ; \mathrm{R}_{3}=\mathrm{R}_{4}=\mathrm{R}_{5}=\mathrm{H} ; \mathrm{R}_{6}=\mathrm{C}_{6} \mathrm{H}_{5}\right.$, Figure 5) demonstrated the highest oxygen sensitivity both in the THF solution and EC film.

On the other hand, $21\left(\mathrm{R}_{1}=\mathrm{R}_{2}=\mathrm{Me} ; \mathrm{R}_{3}=\mathrm{R}_{4}=\mathrm{R}_{5}=\mathrm{H} ; \mathrm{R}_{6}=2,4-\mathrm{C}_{6} \mathrm{H}_{3} \mathrm{~F}_{2}\right.$, Figure 5) demonstrates the highest photostability compared to phenyl-substituted or fluorinated $\mathrm{Pt}(\mathrm{II})$ complexes. Very fast response time $(3.8 \mathrm{~s})$ and recovery time $(4.5 \mathrm{~s})$ were obtained from the $21\left(\mathrm{R}_{1}=\mathrm{R}_{2}=\mathrm{Me} ; \mathrm{R}_{3}=\mathrm{R}_{4}=\mathrm{R}_{5}=\mathrm{H} ; \mathrm{R}_{6}=2,4-\mathrm{C}_{6} \mathrm{H}_{3} \mathrm{~F}_{2}\right.$, Figure 5)-immobilized EC film with an excellent operational stability. These results indicate that the 2,4-difluorophenylsubstituted cyclometalated $\mathrm{Pt}(\mathrm{II})$ complex is a potential OSP for photostable and fastresponsive oxygen sensing devices. In a similar and early study, Liu and coworkers [48] assessed the role of installing trifluoromethyl group at 5-position of pyridine ring on the oxygen sensing and other properties. They noted that the introduction of a strong electron acceptor group improves the oxidation potentials and PLQY of Pt(II) complexes effectively and subsequently reduces photobleaching. In addition, trifluoromethyl substituted $\mathrm{Pt}(\mathrm{II})$ complexes 58 (Figure 14) immobilized in IMPES-C are sensitive to molecular oxygen luminescence intensity changed gradually and reversibly to the $\mathrm{O}_{2}$ concentrations. An extremely fast response time and recovery time of oxygen sensing films were obtained in $4.0 \mathrm{~s}$ and $6.0 \mathrm{~s}$, respectively. A very first example of a switchable AIE-active luminogen 59 (Figure 14) has been recently reported that showed excellent sensitivity towards $\mathrm{O}_{2}$ [94]. A complex-embedded EC polymer 59 exhibited fast quenching/recovering cycles (Figure 15C).

\subsection{Miscellaneous}

In addition to the above-discussed emerging applications of cyclometalated $\mathrm{Pt}(\mathrm{II})$ complexes, some other intriguing applications have also been demonstrated. This includes the development of biosimulated and visible light-driven photocatalysts, which have tremendous applications in the generation of clean and renewable energy (viz. hydrogen evolution reaction HER). Researchers are working towards the design of polymer dots (Pdots) in which Pt(II) complex unit is pre-synthesized as a co-monomer and then covalently 
linked to a conjugated polymer backbone. The resulting materials often exhibit tunable water solubility.

Chou and workers [9] demonstrated that the rate of HER could be significantly increased (up to $12 \times$ ) when a cycloplatinated core is covalently attached to the Pdots (60, Figure 16). Increasing the mole fraction of the $\mathrm{Pt}(\mathrm{II})$-containing unit in polymer poly $\left[\left(9,9^{\prime}\right.\right.$-dioctylfluorenyl2,7-diyl)-co-(6,7-difluoro-2,3-bis(3-(hexyloxy)phenyl)-5,8-di(thiophen-2-yl)quinoxaline)] (PFTFQ) from $0 \%$ to $15 \%$ increased the HER rate $\left(1.3-12.7 \mathrm{mmolh}^{-1} \mathrm{~g}^{-1}\right.$, Figure $\left.17 \mathrm{a}\right)$. The performance was much better for covalently linked cycloplatinated Pdots than the physically blended counterpart Pdots (Figure 17b). It was suggested that covalent linking leads to more efficient photoinduced charge separation, as well as an enhancement in the rate of the proton reduction reaction. Furthermore, this system also holds promise as it works under a methanol-free condition, owing to its excellent water dispersibility.

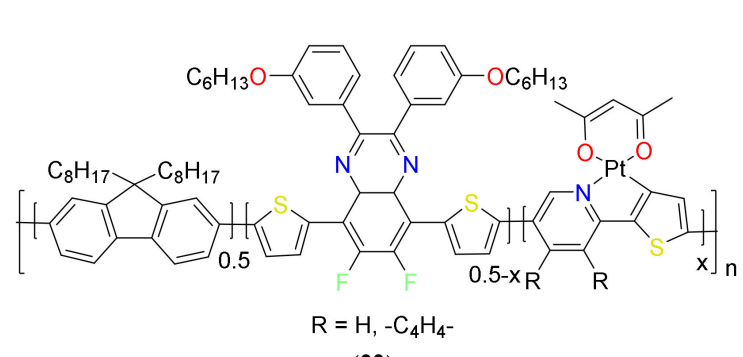

(60)

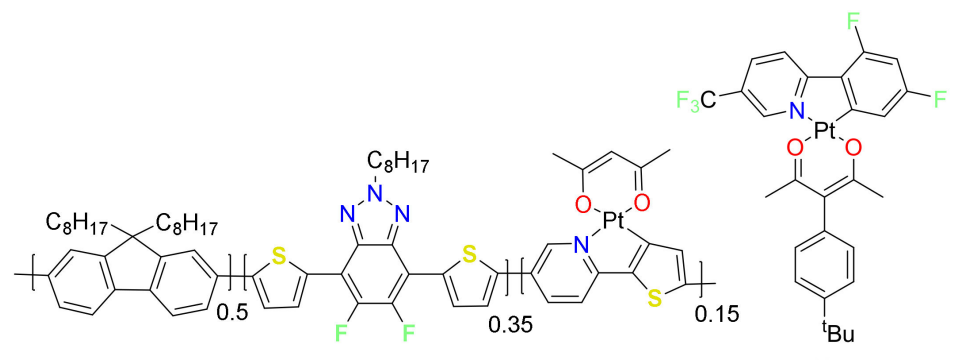

(61)

(62)

Figure 16. Cyclometalated Pt(II) complex-based photocatalysts and others.

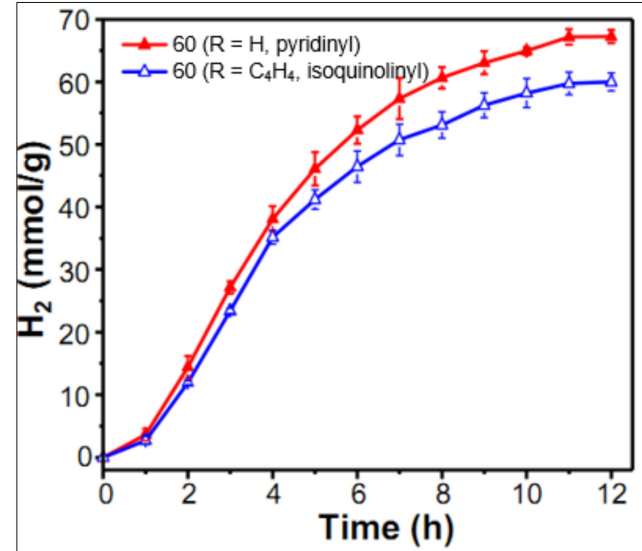

(a)

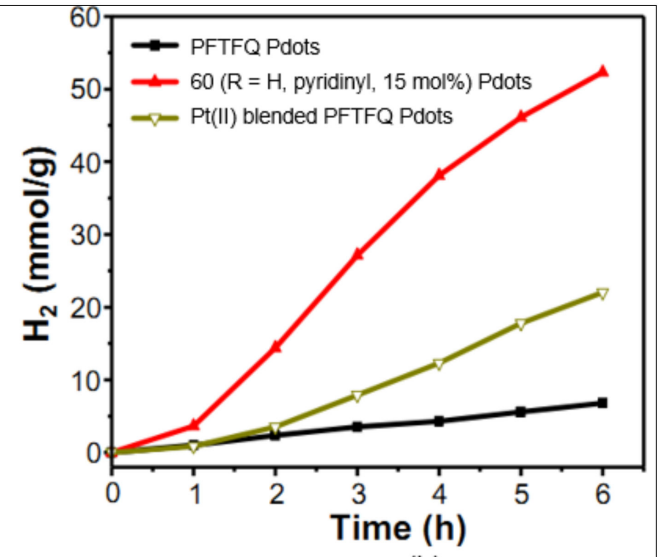

(b)

Figure 17. (a) Time course of produced $\mathrm{H}_{2}$ for 60 (15 mol\%) Pdots for $12 \mathrm{~h}$. (b) Comparison of hydrogen generation of chemically linked 60 Pdots and physically Pt(II)-blended-counterpart PFTFQ Pdots. Reproduced with permission from ref. [9].

To underpin the importance of acceptor comonomers on HER, they systematically studied the effect of cycloplatinated Pdots with various acceptor co-monomers [95]. It was concluded that the introduction of $\mathrm{sp}^{2}$ and $\mathrm{sp}^{3} \mathrm{~N}$-containing acceptor co-monomer into cycloplatinated Pdots dramatically enhances the photocatalytic performance and stability. For instance, polymer dots (Pdots) based on 61 (Figure 16) Pdots provide the excellent HER (up to $7.34 \pm 0.82 \mathrm{mmol} \mathrm{h}^{-1} \mathrm{~g}^{-1}$ ) and enhance performance $(9 \mathrm{~h}$ ) with hydrogen productions of $31.54 \mathrm{mmolg}^{-1}$ compared to the pristine Pdots. The catalysis was carried out under a methanol-free solution and visible light-driven system and showed excellent reusability. It was also shown that the covalent linking strategy is better in terms of toxicity reduction as it poses less side effects than the system containing Pt nanoparticles into a solution system. Some other reports are also available on the applications of cyclometalated $\mathrm{Pt}(\mathrm{II})$ complexes in the area of data security storage [96], nonvolatile photomemories [97], 
NLOs [98], light electrochemical cells [63], etc. For example, it has been reported that one of the isomers of complex 62 (Figure 16) shows responsiveness (luminescence switching) against ethanol vapor in a ground state [96].

\section{Conclusions and Outlook}

In this review, we highlighted the structural features, photophysical properties, and applications of cyclometalated $\mathrm{Pt}(\mathrm{II})$ complexes bearing bidentate cyclometalating ligands and $\beta$-diketonate ancillary ligands, i.e., $\left(\mathrm{C}^{\wedge} \mathrm{N}\right) \mathrm{Pt}\left(\mathrm{O}^{\wedge} \mathrm{O}\right)$ and $\left(\mathrm{C}^{\wedge} \mathrm{C}\right) \mathrm{Pt}\left(\mathrm{O}^{\wedge} \mathrm{O}\right)$ derivatives. Benefitting from the heavy metal effect of platinum and the strong field nature of the cyclometalating ligands, this class of compounds offers easy synthetic pathways, bright and persistent luminescence, stable and strong phosphorescence, wide scope for structural modification, etc. Using pertinent examples, we showed that new functional materials could be realized by a judicious interplay between covalent and noncovalent interactions as well as altering molecular separation/stacking, which is achievable via ancillary as well as cyclometalating ligands. Overall facile structural modification, good water dispersivity, tunable optoelectronic properties make this class of compounds really impressive.

In terms of applications, we have shown that these materials are potential candidates for O-E devices. Several new and highly efficient materials have been developed in the last few years, having the potential to replace fullerene (an acceptor) from the OPVs and single dopants for OLEDs. Moreover, these complexes/units are being installed over large macromolecules (polymers) and converted to Pdots to be used as photocatalysts for the production of molecular hydrogen, which is in high demand and a cleaner source of energy. The newly reported photocatalysts have been found to be safe in nature, stable and reusable. Some researchers suggested their applicability for the development of nonvolatile memory and data security storage. Owing to their multicolor temperatureresponsive emissions $[49,50]$, they are also potential candidates for temperature sensing and nanophotonics.

Future work includes, but is not limited to, the exploration of newly synthesized ligands (viz. synthesis of bulky diketones and extended cyclometalating ligands), synthesis of homo- and hetero multi-metallic complexes, etc. Due to their extended absorption and emission features coupled with low toxicity, they are potential candidates for bioimaging. Especially complexes sensitive to oxygen are particularly interesting for hypoxic imaging tumors. Various studies have demonstrated that the PV performance can be drastically improved, if not all times, by changing the donor/acceptor active layers. Therefore, those materials that have been used as acceptors and shown moderate efficiency in all PSCs should be analyzed with different donor polymers.

Author Contributions: Conceptualization, A.H., M.S.K. and W.-Y.W.; methodology, A.H. and H.E.M.; data curation, A.H., H.E.M. and K.M.A.; writing-original draft preparation, A.H., H.E.M. and K.M.A.; writing-A.H., M.S.K. and W.-Y.W.; visualization, M.S.K. and W.-Y.W.; supervision, M.S.K. and W.-Y.W.; funding acquisition, A.H. All authors have read and agreed to the published version of the manuscript.

Funding: This research was funded by Deputy for Research \& Innovation, Ministry of Education in Saudi Arabia, grant number RDO-2001.

Institutional Review Board Statement: Not applicable.

Informed Consent Statement: Not applicable.

Data Availability Statement: No new data were created in this study.

Acknowledgments: The authors extend their appreciation to the Deputy for Research \& Innovation, Ministry of Education in Saudi Arabia for funding this research work through the project number RDO-2001.

Conflicts of Interest: The authors declare no conflict of interest. 


\section{References}

1. Bischoff, L.; Baudequin, C.; Hoarau, C.; Urriolabeitia, E.P. Organometallic fluorophores of $\mathrm{d}^{8}$ metals (Pd, Pt, Au). Adv. Organomet. Chem. 2018, 69, 73-134.

2. Xu, H.; Chen, R.; Sun, Q.; Lai, W.; Su, Q.; Huang, W.; Liu, X. Recent progress in metal-organic complexes for optoelectronic applications. Chem. Soc. Rev. 2014, 43, 3259-3302. [CrossRef] [PubMed]

3. Chi, Y.; Chou, P.-T. Transition-metal phosphors with cyclometalating ligands: Fundamentals and applications. Chem. Soc. Rev. 2010, 39, 638-655. [CrossRef] [PubMed]

4. Tang, M.-C.; Chan, A.K.-W.; Chan, M.-Y.; Yam, V.W.-W. Platinum and gold complexes for OLEDs. Photolumin. Mater. Electrolumin. Devices 2017, 374, 67-109.

5. Cebrián, C.; Mauro, M. Recent advances in phosphorescent platinum complexes for organic light-emitting diodes. Beilstein J. Org. Chem. 2018, 14, 1459-1481. [CrossRef]

6. Haque, A.; Xu, L.; Al-Balushi, R.A.; Al-Suti, M.K.; Ilmi, R.; Guo, Z.; Khan, M.S.; Wong, W.-Y.; Raithby, P.R. Cyclometalated tridentate platinum (II) arylacetylide complexes: Old wine in new bottles. Chem. Soc. Rev. 2019, 48, 5547-5563. [CrossRef] [PubMed]

7. Haque, A.; Al-Balushi, R.A.; Al-Busaidi, I.J.; Khan, M.S.; Raithby, P.R. Rise of conjugated poly-ynes and poly(metalla-ynes): From design through synthesis to structure-property relationships and applications. Chem. Rev. 2018, 118, 8474-8597. [CrossRef]

8. Yersin, H.; Rausch, A.F.; Czerwieniec, R.; Hofbeck, T.; Fischer, T. The triplet state of organo-transition metal compounds. Triplet harvesting and singlet harvesting for efficient OLEDs. Coord. Chem. Rev. 2011, 255, 2622-2652. [CrossRef]

9. Tseng, P.-J.; Chang, C.-L.; Chan, Y.-H.; Ting, L.-Y.; Chen, P.-Y.; Liao, C.-H.; Tsai, M.-L.; Chou, H.-H. Design and synthesis of cycloplatinated polymer dots as photocatalysts for visible-light-driven hydrogen evolution. ACS Catal. 2018, 8, 7766-7772. [CrossRef]

10. Shen, W.; Zhang, W.; Zhu, C. Theoretical study of the substituent effect controlling the radiative and non-radiative decay processes of platinum (II) complexes. Phys. Chem. Chem. Phys. 2017, 19, 23532-23540. [CrossRef]

11. Stipurin, S.; Strassner, T. Phosphorescent cyclometalated platinum (II) imidazolinylidene complexes. Eur. J. Inorg. Chem. 2021, 9, 804-813. [CrossRef]

12. Hang, X.C.; Fleetham, T.; Turner, E.; Brooks, J.; Li, J. Highly efficient blue-emitting cyclometalated platinum (II) complexes by judicious molecular design. Angew. Chem. 2013, 125, 6885-6888. [CrossRef]

13. Koshevoy, I.O.; Krause, M.; Klein, A. Non-covalent intramolecular interactions through ligand-design promoting efficient photoluminescence from transition metal complexes. Coord. Chem. Rev. 2020, 405, 213094. [CrossRef]

14. Strassner, T. Phosphorescent platinum (II) complexes with $C^{\wedge} C^{*}$ cyclometalated NHC ligands. Acc. Chem. Res. 2016, 49, 2680-2689. [CrossRef]

15. Goswami, S.; Winkel, R.W.; Alarousu, E.; Ghiviriga, I.; Mohammed, O.F.; Schanze, K.S. Photophysics of organometallic platinum (II) derivatives of the diketopyrrolopyrrole chromophore. J. Phys. Chem. A 2014, 118, 11735-11743. [CrossRef] [PubMed]

16. Hao, Z.; Zhang, K.; Chen, K.; Wang, P.; Lu, Z.; Zhu, W.; Liu, Y. More efficient spin-orbit coupling: Adjusting the ligand field strength to the second metal ion in asymmetric binuclear platinum (II) configurations. Dalton Trans. 2020, 49, 8722-8733. [CrossRef]

17. Pittkowski, R.; Strassner, T. Enhanced quantum yields by sterically demanding aryl-substituted $\beta$-diketonate ancillary ligands. Beilstein J. Org. Chem. 2018, 14, 664-671. [CrossRef] [PubMed]

18. Leopold, H.; Heinemeyer, U.; Wagenblast, G.; Münster, I.; Strassner, T. Changing the emission properties of phosphorescent $\mathrm{C}^{\wedge} \mathrm{C}^{*}$-cyclometalated thiazol-2-ylidene platinum (II) complexes by variation of the $\beta$-diketonate ligands. Chem. Eur. J. 2017, 23, 1118-1128. [CrossRef]

19. Yan, Y.; Yu, Z.; Liu, C.; Jin, X. Effects of phenyl/thienyl substituents at acetylacetone auxiliary ligands on the properties of cyclometalated platinum (II) complexes. Dye. Pigm. 2020, 173, 107949. [CrossRef]

20. Qian, G.; Yang, X.; Wang, X.; Herod, J.D.; Bruce, D.W.; Wang, S.; Zhu, W.; Duan, P.; Wang, Y. Chiral platinum-based metallomesogens with highly efficient circularly polarized electroluminescence in solution-processed organic light-emitting diodes. Adv. Opt. Mat. 2020, 8, 2000775. [CrossRef]

21. Heil, A.; Marian, C.M. Structure-emission property relationships in cyclometalated Pt (II) $\beta$-diketonate complexes. Inorg. Chem. 2019, 58, 6123-6136. [CrossRef]

22. Huo, S.; Carroll, J.; Vezzu, D.A. Design, synthesis, and applications of highly phosphorescent cyclometalated platinum complexes. Asian J. Org. Chem. 2015, 4, 1210-1245. [CrossRef]

23. Tenne, M.; Metz, S.; Wagenblast, G.; Münster, I.; Strassner, T. C^C Cyclometalated platinum (II) complexes with dibenzofuranyl-1, 2, 4-triazol-5-ylidene ligands: Synthesis, characterization, and photoluminescent properties. Organometallics 2015, 34, 4433-4440. [CrossRef]

24. Pinter, P.; Strassner, T. Prediction of emission wavelengths of phosphorescent NHC based emitters for OLEDs. Tetrahedron 2019, 75, 130431. [CrossRef]

25. Jiang, X.; Chen, G.-H.; Gu, M.-Q.; Wang, Q.; Wu, D. Theoretical study and design of phosphorescent cyclometalated $\left(\mathrm{C}^{\wedge} \mathrm{C}^{*}\right)$ $\mathrm{Pt}^{\mathrm{II}}$ (acac) Complexes: The substituent effect controls the radiative and nonradiative decay processes. J. Phys. Chem. A 2017, 121, 6231-6242. [CrossRef] 
26. Lanoë, P.-H.; Moreno-Betancourt, A.; Wilson, L.; Philouze, C.; Monnereau, C.; Jamet, H.; Jouvenot, D.; Loiseau, F. Neutral heteroleptic cyclometallated platinum (II) complexes featuring 2-phenylbenzimidazole ligand as bright emitters in solid state and in solution. Dye. Pigment. 2019, 162, 967-977. [CrossRef]

27. Hopkinson, M.N.; Richter, C.; Schedler, M.; Glorius, F. An overview of N-heterocyclic carbenes. Nature 2014, 510, 485-496. [CrossRef]

28. Tronnier, A.; Schleicher, D.; Strassner, T. (C`C*)-cyclometalated platinum (II) imidazo [1, 5-a] pyridine NHC complexes-Synthesis and characterization. J. Organomet. Chem. 2015, 775, 155-163. [CrossRef]

29. Tronnier, A.; Heinemeyer, U.; Metz, S.; Wagenblast, G.; Muenster, I.; Strassner, T. Heteroleptic platinum (II) NHC complexes with a $C^{\wedge} C^{*}$ cyclometalated ligand-Synthesis, structure and photophysics. J. Mater. Chem. C 2015, 3, 1680-1693. [CrossRef]

30. Tronnier, A.; Nischan, N.; Metz, S.; Wagenblast, G.; Münster, I.; Strassner, T. Phosphorescent $\mathrm{C}^{\wedge} \mathrm{C}^{*} \mathrm{Cyclometalated} \mathrm{Pt} \mathrm{II}^{\mathrm{II}}$ dibenzofuranyl-NHC complexes-An auxiliary ligand study. Eur. J. Inorg. Chem. 2014, 2014, 256-264. [CrossRef]

31. Unger, Y.; Meyer, D.; Molt, O.; Schildknecht, C.; Münster, I.; Wagenblast, G.; Strassner, T. Green-blue emitters: NHC-based cyclometalated $\mathrm{Pt}\left(\mathrm{C}^{\wedge} \mathrm{C}^{*}\right)(\mathrm{acac})$ complexes. Angew. Chem. Int. Ed. 2010, 49, 10214-10216. [CrossRef]

32. Pinter, P.; Mangold, H.; Stengel, I.; Münster, I.; Strassner, T. Enhanced photoluminescence quantum yields through excimer formation of cyclometalated platinum (II) N-heterocyclic carbene complexes. Organometallics 2016, 35, 673-680. [CrossRef]

33. Fuertes, S.; Chueca, A.J.; Martín, A.; Sicilia, V. Pt 2 Tl building blocks for two-dimensional extended solids: Synthesis, crystal structures, and luminescence. Cryst. Growth Des. 2017, 17, 4336-4346. [CrossRef]

34. Soellner, J.; Strassner, T. Phosphorescent cyclometalated platinum (II) aNHC complexes. Chem. Eur. J. 2018, 24 , 15603-15612. [CrossRef]

35. Fantasia, S.; Petersen, J.L.; Jacobsen, H.; Cavallo, L.; Nolan, S.P. Electronic properties of N-heterocyclic carbene (NHC) ligands: Synthetic, structural, and spectroscopic studies of (NHC) platinum (II) complexes. Organometallics 2007, 26, 5880-5889. [CrossRef]

36. Strassner, T.; Unger, Y.; Meyer, D.; Molt, O.; Münster, I.; Wagenblast, G. The "enders triazole": A well known molecule, but still a new ligand. Inorg. Chem. Commun. 2013, 30,39-41. [CrossRef]

37. Soellner, J.; Strassner, T. The "enders triazole" revisited: Highly efficient, blue platinum (II) emitters. Organometallics 2018, 37, 1821-1824. [CrossRef]

38. Soellner, J.; Strassner, T. Cyclometalated platinum (II) complexes with mesoionic dibenzofuranyl-1, 2, 3-triazol-4-ylidene ligands: Synthesis, characterization and photophysical properties. Chem. Photo. Chem. 2019, 3, 554-558. [CrossRef]

39. Tenne, M.; Metz, S.; Wagenblast, G.; Münster, I.; Strassner, T. $C^{\wedge} C^{*}$ cyclometalated platinum (II) N-heterocyclic carbene complexes with a sterically demanding $\beta$-diketonato ligand-Synthesis, characterization and photophysical properties. Dalton Trans. 2015, 44, 8444-8455. [CrossRef] [PubMed]

40. Soellner, J.; Strassner, T. Mesoionic 1, 2, 3-Triazolo [1, 5-a] pyridine-3-ylidenes in phosphorescent platinum (II) complexes. Chem. Photo. Chem. 2019, 3, 1000-1003. [CrossRef]

41. Leopold, H.; Strassner, T. 4, 5-Substituted $\mathrm{C}^{\wedge} \mathrm{C}^{*}$ cyclometalated thiazol-2-ylidene platinum (II) complexes-Synthesis and photophysical properties. Dalton Trans. 2017, 46, 7800-7812. [CrossRef]

42. Leopold, H.; Tronnier, A.; Wagenblast, G.; Münster, I.; Strassner, T. Photoluminescence of a new material: Cyclometalated C^C thiazole-2-ylidene platinum (II) complexes. Organometallics 2016, 35, 959-971. [CrossRef]

43. Mastrocinque, F.; Anderson, C.M.; Elkafas, A.M.; Ballard, I.V.; Tanski, J.M. Synthesis, characterization, and photophysical properties of cyclometalated N-Heterocyclic carbene platinum (II) complexes. J. Organomet. Chem. 2019, 880, 98-107. [CrossRef]

44. Shigehiro, T.; Chen, Q.; Yagi, S.; Maeda, T.; Nakazumi, H.; Sakurai, Y. Substituent effect on photo-and electroluminescence properties of heteroleptic cyclometalated platinum (II) complexes based on a 2-(dibenzo [b, d] furan-4-yl) pyridine ligand. Dye. Pigment. 2016, 124, 165-173. [CrossRef]

45. Jackel, A.; Linseis, M.; Häge, C.; Winter, R.F. Turning-on of coumarin phosphorescence in acetylacetonato platinum complexes of cyclometalated pyridyl-substituted coumarins. Inorganics 2015, 3, 55-81. [CrossRef]

46. Shafikov, M.Z.; Kozhevnikov, D.N.; Bodensteiner, M.; Brandl, F.; Czerwieniec, R. Modulation of intersystem crossing rate by minor ligand modifications in cyclometalated platinum (II) complexes. Inorg. Chem. 2016, 55, 7457-7466. [CrossRef] [PubMed]

47. Shi, J.; Wang, Y.; Xiao, M.; Zhong, P.; Liu, Y.; Tan, H.; Zhu, M.; Zhu, W. Luminescent metallomesogens based on platinum complex containing triphenylene unit. Tetrahedron 2015, 71, 463-469. [CrossRef]

48. Xing, Y.; Liu, C.; Song, X.; Li, J. Photostable trifluoromethyl-substituted platinum (II) emitters for continuous monitoring of molecular oxygen. J. Mater. Chem. C 2015, 3, 2166-2174. [CrossRef]

49. Zeng, W.; Sun, M.-J.; Gong, Z.-L.; Shao, J.-Y.; Zhong, Y.-W.; Yao, J. Effect of the fluoro-substituent position on the crystal structure and photoluminescence of microcrystals of platinum $\beta$-diketonate complexes. Inorg. Chem. 2020, 59, 11316-11328. [CrossRef] [PubMed]

50. Sun, M.-J.; Liu, Y.; Zeng, W.; Zhao, Y.S.; Zhong, Y.-W.; Yao, J. Photoluminescent anisotropy amplification in polymorphic organic nanocrystals by light-harvesting energy transfer. J. Am. Chem. Soc. 2019, 141, 6157-6161. [CrossRef]

51. Xing, Y.; Liu, C.; Xiu, J.-H.; Li, J.-Y. Photostable fluorophenyl-substituted cyclometalated platinum (II) emitters for monitoring of molecular oxygen in real time. Inorg. Chem. 2015, 54, 7783-7790. [CrossRef] [PubMed]

52. Xing, Y.; Wang, L.; Liu, C.; Jin, X. Effects of fluorine and phenyl substituents on oxygen sensitivity and photostability of cyclometalated platinum (II) complexes. Sens. Actuator B Chem. 2020, 304, 127378. [CrossRef] 
53. Okamura, N.; Maeda, T.; Fujiwara, H.; Soman, A.; Unni, K.N.; Ajayaghosh, A.; Yagi, S. Photokinetic study on remarkable excimer phosphorescence from heteroleptic cyclometalated platinum (II) complexes bearing a benzoylated 2-phenylpyridinate ligand. Phys. Chem. Chem. Phys. 2018, 20, 542-552. [CrossRef]

54. Kang, J.; Zaen, R.; Park, K.-M.; Lee, K.H.; Lee, J.Y.; Kang, Y. Cyclometalated Platinum (ii) $\beta$-diketonate complexes as single dopants for high-efficiency white OLEDs: The relationship between intermolecular interactions in the solid state and electroluminescent efficiency. Cryst. Growth Des. 2020, 20, 6129-6138. [CrossRef]

55. Rozhkov, A.V.; Ananyev, I.V.; Gomila, R.M.; Frontera, A.; Kukushkin, V.Y. $\pi$-Hole $\cdots \mathrm{dz}^{2}\left[\mathrm{Pt}^{\mathrm{II}}\right]$ interactions with electron-deficient arenes enhance the phosphorescence of $\mathrm{Pt}^{\mathrm{II}}$-based luminophores. Inorg. Chem. 2020, 59, 9308-9314. [CrossRef]

56. Zhang, Y.; Chen, Z.; Wang, X.; He, J.; Wu, J.; Liu, H.; Song, J.; Qu, J.; Chan, W.T.-K.; Wong, W.-Y. Achieving NIR emission for donor-acceptor type platinum (II) complexes by adjusting coordination position with isomeric ligands. Inorg. Chem. 2018, 57, 14208-14217. [CrossRef] [PubMed]

57. Usuki, T.; Uchida, H.; Omoto, K.; Yamanoi, Y.; Yamada, A.; Iwamura, M.; Nozaki, K.; Nishihara, H. Enhancement of the photofunction of phosphorescent Pt (II) cyclometalated complexes driven by substituents: Solid-state luminescence and circularly polarized luminescence. J. Org. Chem. 2019, 84, 10749-10756. [CrossRef]

58. Wang, D.; Chen, X.; Yang, H.; Zhong, D.; Liu, B.; Yang, X.; Yue, L.; Zhou, G.; Ma, M.; Wu, Z. The synthesis of cyclometalated platinum (II) complexes with benzoaryl-pyridines as $\mathrm{C}^{\wedge} \mathrm{N}$ ligands for investigating their photophysical, electrochemical and electroluminescent properties. Dalton Trans. 2020, 49, 15633-15645. [CrossRef]

59. Berry, J.F.; Thomas, C.M. Multimetallic complexes: Synthesis and applications. Dalton Trans. 2017, 46, 5472-5473. [CrossRef]

60. Hao, Z.; Meng, F.; Wang, P.; Wang, Y.; Tan, H.; Pei, Y.; Su, S.; Liu, Y. Dual phosphorescence emission of dinuclear platinum (II) complex incorporating cyclometallating pyrenyl-dipyridine-based ligand and its application in near-infrared solution-processed polymer light-emitting diodes. Dalton Trans. 2017, 46, 16257-16268. [CrossRef]

61. Zhang, K.; Wang, T.; Wu, T.; Ding, Z.; Zhang, Q.; Zhu, W.; Liu, Y. An effective strategy to obtain near-infrared emission from shoulder to shoulder-type binuclear platinum (ii) complexes based on fused pyrene core bridged isoquinoline ligands. J. Mater. Chem. C 2021, 9, 2282-2290. [CrossRef]

62. Zhang, K.; Liu, Y.; Hao, Z.; Lei, G.; Cui, S.; Zhu, W.; Liu, Y. A feasible approach to obtain near-infrared (NIR) emission from binuclear platinum (II) complexes containing centrosymmetric isoquinoline ligand in PLEDs. Org. Electron. 2020, 87, 105902. [CrossRef]

63. Shafikov, M.Z.; Tang, S.; Larsen, C.; Bodensteiner, M.; Kozhevnikov, V.N.; Edman, L. An efficient heterodinuclear Ir(III)/Pt (II) complex: Synthesis, photophysics and application in light-emitting electrochemical cells. J. Mater. Chem. C 2019, 7, 10672-10682 [CrossRef]

64. Yang, X.; Jiao, B.; Dang, J.-S.; Sun, Y.; Wu, Y.; Zhou, G.; Wong, W.-Y. Achieving high-performance solution-processed orange OLEDs with the phosphorescent cyclometalated trinuclear Pt (II) complex. ACS Appl. Mater. Interfaces 2018, 10, 10227-10235. [CrossRef]

65. Rappaport, P. The photovoltaic effect and its utilization. Sol. Energy 1959, 3, 8-18. [CrossRef]

66. Wright, M.; Uddin, A. Organic-Inorganic hybrid solar cells: A comparative review. Sol. Energy Mater. Sol. Cells 2012, 107, 87-111. [CrossRef]

67. Thompson, B.C.; Fréchet, J.M. Polymer-fullerene composite solar cells. Angew. Chem. Int. Ed. 2008, 47, 58-77. [CrossRef] [PubMed]

68. Günes, S.; Neugebauer, H.; Sariciftci, N.S. Conjugated polymer-based organic solar cells. Chem. Rev. 2007, 107, 1324-1338. [CrossRef]

69. Li, G.; Zhu, R.; Yang, Y. Polymer solar cells. Nat. Photonics 2012, 6, 153-161. [CrossRef]

70. Wang, T.; Kupgan, G.; Brédas, J.L. Organic photovoltaics: Relating chemical structure, local morphology, and electronic properties. Trends Chem. 2020, 2, 535-554. [CrossRef]

71. Al-Busaidi, I.J.; Haque, A.; Al Rasbi, N.K.; Khan, M.S. Phenothiazine-based derivatives for optoelectronic applications: A review. Synth. Met. 2019, 257, 116189. [CrossRef]

72. Guo, F.; Kim, Y.-G.; Reynolds, J.R.; Schanze, K.S. Platinum-acetylide polymer based solar cells: Involvement of the triplet state for energy conversion. Chem. Commun. 2006, 17, 1887-1889. [CrossRef]

73. Yang, C.-M.; Wu, C.-H.; Liao, H.-H.; Lai, K.-Y.; Cheng, H.-P.; Horng, S.-F.; Meng, H.-F.; Shy, J.-T. Enhanced photovoltaic response of organic solar cell by singlet-to-triplet exciton conversion. Appl. Phys. Lett. 2007, 90, 133509. [CrossRef]

74. Zhao, X.; Piliego, C.; Kim, B.; Poulsen, D.A.; Ma, B.; Unruh, D.A.; Fréchet, J.M. Solution-processable crystalline platinum-acetylide oligomers with broadband absorption for photovoltaic cells. Chem. Mater. 2010, 22, 2325-2332. [CrossRef]

75. Felter, K.M.; Caselli, V.M.; Günbaş, D.D.; Savenije, T.J.; Grozema, F.C. Interplay between charge carrier mobility, exciton diffusion, crystal packing, and charge separation in perylene diimide-based heterojunctions. ACS Appl. Energy Mater. 2019, 2, 8010-8021. [CrossRef]

76. Clem, T.A.; Kavulak, D.F.; Westling, E.J.; Fréchet, J.M. Cyclometalated platinum polymers: Synthesis, photophysical properties, and photovoltaic performance. Chem. Mater. 2010, 22, 1977-1987. [CrossRef]

77. Liao, C.-Y.; Chen, C.-P.; Chang, C.-C.; Hwang, G.-W.; Chou, H.-H.; Cheng, C.-H. Synthesis of conjugated polymers bearing indacenodithiophene and cyclometalated platinum (II) units and their application in organic photovoltaics. Sol. Energy Mater. Sol. Cells 2013, 109, 111-119. [CrossRef] 
78. Goswami, S.; Gish, M.K.; Wang, J.; Winkel, R.W.; Papanikolas, J.M.; Schanze, K.S. $\pi$-Conjugated organometallic isoindigo oligomer and polymer chromophores: Singlet and triplet excited state dynamics and application in polymer solar cells. ACS Appl. Mater. Interfaces 2015, 7, 26828-26838. [CrossRef]

79. Goswami, S.; Hernandez, J.L.; Gish, M.K.; Wang, J.; Kim, B.; Laudari, A.P.; Guha, S.; Papanikolas, J.M.; Reynolds, J.R.; Schanze, K.S. Cyclometalated platinum-containing diketopyrrolopyrrole complexes and polymers: Photophysics and photovoltaic applications. Chem. Mater. 2017, 29, 8449-8461. [CrossRef]

80. Wan, Z.; Yang, J.; Liu, Y.; Wang, S.; Zhong, Y.; Li, C.; Zhang, Z.; Xing, G.; Huettner, S.; Tao, Y.; et al. Cyclometalated Pt complex-based random terpolymers for efficient polymer solar cells. Polym. Chem. 2017, 8, 4729-4737. [CrossRef]

81. Gao, X.; Liang, Y.; Wang, H.; Yang, T.; Huettner, S.; Wang, J.; Zhu, F.; Tao, Y. Terpolymer acceptors based on an organic ligand or corresponding cyclometalated Pt complex for all polymer solar cells. Org. Electron. 2019, 70, 93-100. [CrossRef]

82. Gao, X.; Wang, M.; Cao, X.; Yang, J.; Zhong, Y.; Zhang, Z.; Li, C.; Huettner, S.; Tao, Y.; Li, Y. Cyclometalated Pt complex based random terpolymers as electron acceptors for all polymer solar cells. J. Polym. Sci. Part A Polym. Chem. 2018, 56, 105-115. [CrossRef]

83. Gao, X.; Shi, D.; Wang, M.; Xue, Z.; Hu, Y.; Tao, Y.; Huang, W. Pt complex-based terpolymer acceptors linked through ancillary ligand for all-polymer solar cells. J. Mater. Chem. C 2018, 6, 9903-9913. [CrossRef]

84. Fan, C.; Yang, C. Yellow/orange emissive heavy-metal complexes as phosphors in monochromatic and white organic lightemitting devices. Chem. Soc. Rev. 2014, 43, 6439-6469. [CrossRef] [PubMed]

85. Sun, Y.; Liu, B.; Guo, Y.; Feng, Z.; Zhou, G.; Chen, Z.; Yang, X. Triphenylamine-based trinuclear Pt (II) complexes for solutionprocessed OLEDs displaying efficient pure yellow and red emissions. Org. Electron. 2021, 91, 106101. [CrossRef]

86. Tronnier, A.; Strassner, T. ( $\left.\mathrm{C}^{\wedge} \mathrm{C}^{*}\right)$ Cyclometalated binuclear N-heterocyclic biscarbene platinum (II) complexes-Highly emissive phosphorescent emitters. Dalton Trans. 2013, 42, 9847-9851. [CrossRef] [PubMed]

87. Okamura, N.; Egawa, K.; Maeda, T.; Yagi, S. Control of excimer phosphorescence by steric effects in cyclometalated platinum (ii) diketonate complexes bearing peripheral carbazole moieties towards application in non-doped white OLEDs. New J. Chem. 2018, 42, 11583-11592. [CrossRef]

88. Wei, Z.; Zhang, K.; Kim, C.K.; Tan, S.; Wang, S.; Wang, L.; Li, J.; Wang, Y. Stimuli-responsive cyclometalated platinum complex bearing bent molecular geometry for highly efficient solution-processable OLEDs. Chin. Chem. Lett. 2021, 32, 493-496. [CrossRef]

89. Petrenko, A.; Leitonas, K.; Volyniuk, D.; Baryshnikov, G.V.; Belyakov, S.; Minaev, B.F.; Ågren, H.; Durgaryan, H.; Gražulevičius, J.V.; Arsenyan, P. Benzoselenophenylpyridine platinum complexes: Green versus red phosphorescence towards hybrid OLEDs. Dalton Trans. 2020, 49, 3393-3397. [CrossRef]

90. Li, H.Y.; Zhao, S.N.; Zang, S.Q.; Li, J. Functional metal-organic frameworks as effective sensors of gases and volatile compounds. Chem. Soc. Rev. 2020, 49, 6364-6401. [CrossRef]

91. Wu, W.; Cheng, C.; Wu, W.; Guo, H.; Ji, S.; Song, P.; Han, K.; Zhao, J.; Zhang, X.; Wu, Y. Tuning the emission colour of triphenylamine-capped cyclometallated platinum (II) complexes and their application in luminescent oxygen sensing and organic light-emitting diodes. Eur. J. Inorg. Chem. 2010, 2010, 4683-4696. [CrossRef]

92. Liu, C.; Song, X.; Wang, Z.; Qiu, J. 2-Phenylquinoline-Based cyclometalated platinum (II) complexes: Synthesis and structurephotoelectric properties relationship in oxygen sensing. Chem. Plus. Chem 2014, 79, 1472-1481. [CrossRef]

93. Liu, C.; Song, X.; Rao, X.; Xing, Y.; Wang, Z.; Zhao, J.; Qiu, J. Novel triphenylamine-based cyclometalated platinum (II) complexes for efficient luminescent oxygen sensing. Dye. Pigment. 2014, 101, 85-92. [CrossRef]

94. Di, L.; Xia, Z.; Wang, H.; Xing, Y.; Yang, Z. Switchable and adjustable AIE activity of Pt (II) complexes achieving swift-responding and highly sensitive oxygen sensing. Sens. Actuator B Chem. 2021, 326, 128987. [CrossRef]

95. Chang, C.-L.; Lin, W.-C.; Jia, C.-Y.; Ting, L.-Y.; Jayakumar, J.; Elsayed, M.H.; Yang, Y.-Q.; Chan, Y.-H.; Wang, W.-S.; Lu, C.-Y. Low-toxic cycloplatinated polymer dots with rational design of acceptor co-monomers for enhanced photocatalytic efficiency and stability. Appl. Catal. B Environ. 2020, 268, 118436. [CrossRef]

96. Gao, L.; Ni, J.; Su, M.; Kang, J.; Zhang, J. Luminescence switching property of cycloplatinated (II) complexes bearing 2phenylpyridine derivatives and the application for data security storage. Dye. Pigment. 2019, 165, 231-238. [CrossRef]

97. Liao, M.-Y.; Elsayed, M.H.; Chang, C.-L.; Chiang, Y.-C.; Lee, W.-Y.; Chen, W.-C.; Chou, H.-H.; Chueh, C.-C. Realizing nonvolatile photomemories with multilevel memory behaviors using water-processable polymer dots-based hybrid floating gates. ACS Appl. Electron. Mater. 2021, 3, 1708-1718. [CrossRef]

98. Liu, Z.; Sun, J.; Yan, C.; Xie, Z.; Zhang, G.; Shao, X.; Zhang, D.; Zhou, S. Diketopyrrolopyrrole based donor-acceptor $\pi$-conjugated copolymers with near-infrared absorption for 532 and $1064 \mathrm{~nm}$ nonlinear optical materials. J. Mater. Chem. C. 2020, 8, 12993-13000. [CrossRef] 